\title{
JULES-GL7: the Global Land configuration of the Joint UK Land Environment Simulator version 7.0 and 7.2
}

\author{
Andrew J. Wiltshire ${ }^{1,2}$, Maria Carolina Duran Rojas ${ }^{2}$, John M. Edwards ${ }^{1}$, Nicola Gedney ${ }^{1}$, Anna B. Harper ${ }^{2}$, \\ Andrew J. Hartley ${ }^{1}$, Margaret A. Hendry ${ }^{1}$, Eddy Robertson ${ }^{1}$, and Kerry Smout-Day ${ }^{1}$ \\ ${ }^{1}$ Met Office, Fitzroy Road, Exeter, UK \\ ${ }^{2}$ University of Exeter, Exeter, UK
}

Correspondence: Andrew J. Wiltshire (andy.wiltshire@ metoffice.gov.uk)

Received: 24 May 2019 - Discussion started: 12 July 2019

Revised: 8 November 2019 - Accepted: 28 November 2019 - Published: 7 February 2020

\begin{abstract}
We present the latest global land configuration of the Joint UK Land Environment Simulator (JULES) model as used in the latest international Coupled Model Intercomparison Project (CMIP6). The configuration is defined by the combination of switches, parameter values and ancillary data, which we provide alongside a set of historical forcing data that defines the experimental setup. The configurations provided are JULES-GL7.0, the base setup used in CMIP6 and JULES-GL7.2, a subversion that includes improvements to the representation of canopy radiation and interception. These configurations are recommended for all JULES applications focused on the exchange and state of heat, water and momentum at the land surface.

In addition, we provide a standardised modelling system that runs on the Natural Environment Research Council (NERC) JASMIN cluster, accessible to all JULES users. This is provided so that users can test and evaluate their own science against the standard configuration to promote community engagement in the development of land surface modelling capability through JULES. It is intended that JULES configurations should be independent of the underlying code base, and thus they will be available in the latest release of the JULES code. This means that different code releases will produce scientifically comparable results for a given configuration version. Versioning is therefore determined by the configuration as opposed to the underlying code base.
\end{abstract}

\section{Introduction}

The Joint UK Land Environment Simulator (JULES) (Best et al., 2011; Clark et al., 2011) is the land surface model used by the UK land, hydrological, weather and climate communities. JULES is a comprehensive model simulating the atmospheric exchange of radiation, heat, water, momentum, carbon and methane and changes in the surface states of moisture, heat and carbon. All these processes are important for the wide-ranging application of JULES from carbon cycle (Le Quéré et al., 2018) to climate impact (Shannon et al., 2019) and hydrological (Betts et al., 2018) modelling. However, each of these applications is best suited to a combination of different processes and schemes; for instance, an interactive dynamic vegetation model is important for understanding carbon cycle processes but not crucial to crop modelling (Osborne et al., 2015) and may introduce additional biases and errors. The JULES code base enables a vast number of different setups through parameter and switch combinations, many of which are undesirable for a plethora of reasons from poor performance, lack of testing or incompatibility between options. This can lead to very poor scientific outcomes if the user is not completely familiar with the JULES code base. Addressing this is best achieved by having defined "science configurations", specifying a particular combination of parameters and switches that are known to produce appropriate, well-evaluated and tested results.

JULES is the land component of the Met Office modelling system, which is used across weather to climate timescales. Each component has defined configurations: the global atmosphere (GA) for configurations of the atmospheric model, global land (GL) configuration for JULES, and likewise for 
the ocean and sea-ice components, with the global coupled (GC) configuration for the fully coupled atmosphere, ocean, sea-ice and land model. Here, we present the JULES-GL7 configuration family, developed primarily as part of the atmosphere model at the Met Office. JULES-GL7.0 is the offline version of the GL7.0 configuration used in conjunction with GA7.0 (Walters et al., 2019), the atmospheric configuration of the Met Office. These are the latest iterations in the GA/GL configuration series developed for use in global modelling and underpin the HadGEM3-GC3.1 (Williams et al., 2018) model that is being used as part of the sixth iteration of the Coupled Model Intercomparison Project (CMIP6) (Eyring et al., 2016). The GL7.0 configuration is specifically developed to simulate the exchange of heat, water and momentum generally known as the "physical environment" and therefore does not include biogeochemical components which come under "Earth system" modelling, nor does it include processes specifically related to climate impacts such as crops. It is the appropriate configuration for understanding hydrology and land surface processes relating to the partitioning of heat and radiation. In many ways, GL7.0 is the core JULES configuration; for example, the Earth system setup adds components to it to enable the simulation of the exchange of carbon and methane. We also describe a subversion (JULES-GL7.2), which includes an improved canopy radiation scheme and diffuse radiation effects. This version addresses some known issues in the treatment of radiative transfer through the canopy.

Although this is the first time a stand-alone standard configuration of JULES is being made available to the community, land configurations are widely established in weather and climate modelling. The predecessor to JULES was the Met Office Surface Exchange Scheme (MOSES; Cox et al., 1999). Configurations of MOSES2.2 (Essery et al., 2003) underpin the CMIP5 physical model, HadGEM2 (The HadGEM2 Development Team, 2011) and the Earth system model HadGEM2-ES (Collins et al., 2011). As of GL3 (Walters et al., 2011), configurations of JULES were introduced and have been developed over subsequent iterations of the model development cycle, the latest of which is GL7, as described here offline and as coupled to the atmosphere (Walters et al., 2019) and ocean (Williams et al., 2018). Future configurations are currently in development with the aim of reducing model biases and improving the representation of physical processes. For instance, GL8 will include updated snow process representation, including a new scheme parameterising snow grain size growth (Taillandier et al., 2007) with the aim of reducing albedo biases over the Antarctic and Greenland ice sheets, and GL9 to include improved spatially varying observationally based canopy height. Alternative examples of configurations have previously been made available to the community as a stop-gap measure but the provenance of these is unknown and has resulted in a number of cases of poor performance. The release of JULES-GL7 is part of an activity to ensure integrity of science results and enhance future development and capability of JULES land surface modelling.

Here, we document the offline JULES-GL7 configurations and their release at JULES vn5.3. The release includes a standardised suite control setup to initialise, reconfigure, spinup and run a standard historical experiment. The release is designed to be as easy as possible to access and run on the NERC JASMIN platform (http://www.jasmin.ac.uk/, last access: 31 January 2020). Further details on running the JULES-GL7 configurations are given in Appendix A. The provision of standard configurations is an important step in the ongoing aim for community development of configurations underpinning weather, climate, hydrological and impact modelling in the UK. Future developments will include improved benchmarking and evaluation tools.

\section{JULES configurations}

Defining JULES configurations and how they should be used and developed is therefore an essential component of improving land surface modelling. At the core of an application is the science configuration, which is the collection of parameters, ancillaries and switches necessary to produce the same results for a given experimental setup. The experimental setup covers the necessary model forcing information to produce a simulation. For example, the setup provided here uses historical meteorological information to perform a simulation from the pre-industrial to the present day at n96 $\left(1.875^{\circ} \times 1.25^{\circ}\right)$ resolution. Alternative experimental setups may be running future scenarios such as those included in CMIP6 (Eyring et al., 2016). The third component provided here is a standardised way by which the science and experimental configuration can be set up and run, and is largely provided to support ease of access and use by a diverse range of users. This done by way of a suite compatible with the Rose/Cylc suite control system (https://metomi.github. io/rose/doc/html/index.html, last access: 31 January 2020) available on JASMIN. The control system orchestrates the flow of interdependent tasks (workflow) from the initial extraction of the source code from repository, subsequent build and installation of the science and experimental setups and finally controls the simulation on the compute platform. The suite is the collection of all the information to make a simulation from start to finish in a format compatible with the workflow manager and a user-friendly graphical user interface.

JULES is a configurable model in which a named set of values control the operation of the model. JULES as a code base can support a number of these value sets that define different configurations. An important concept in the development of JULES-GL configurations is the independence of configuration from code release. JULES is managed to ensure that new developments in the code base produce scientifically comparable results. This is not exactly the same as being reproducible to the bit level, as some changes are per- 
mitted, for example, technical changes to the code base that result in explainable bit-level changes. From a user perspective, the differences between model releases should be pragmatically indistinguishable for a given configuration. The easiest way to ensure this is for new developments to be put onto a switch. JULES-GL7 will be available at subsequent model versions and tested to ensure the setup produces scientifically comparable results between model code base versions until a date when JULES-GL7 is superseded and retired. A second concept is that JULES as a code base can support multiple configurations dependent on the desired application. The two major configurations are global land and Earth system. The Earth system extends the global land to include biogeochemical processes important to understanding feedbacks in the climate system.

The ancillary data component or ancillaries of a configuration are the spatially explicit information that varies according to the site or from grid box to grid box in the case of a gridded run. An example of this would be land cover. In the case of a gridded experiment, these data are typically derived from high-resolution satellite- or observation-based sources, which have to be post-processed to meet the requirements of JULES. The exact ancillary data vary according to the experimental setup (i.e. resolution, individual site, etc.), but as far as possible the mechanism by which the JULES-specific information is derived from the source data is part of the science configuration. In the case of land cover in GL7, this would include the aggregation of land cover types into surface tile types from International Geosphere-Biosphere Programme (IGBP) maps (Sect. 2.1). Here, we include a description of the ancillary generation process and include the ancillaries for an $\mathrm{n} 96$ experimental configuration simulating the 20th century.

The JULES suites and online resources are available via the Met Office Science Repository Service (MOSRS) (https://code.metoffice.gov.uk, last access: 31 January 2020, login required) and are freely available subject to completion of a software licence (Appendix A). Living documentation of the latest suite version can be found at https://code.metoffice.gov.uk/trac/jules/wiki/ JulesConfigurations (last access: 31 January 2020) (login required).

\section{JULES-GL7 configuration}

This section describes the offline JULES-GL7.0 and JULESGL7.2 science configurations. An important difference between the offline and coupled versions is that in the coupled version JULES acts as an interface between land (including land ice), sea ice and the ocean, whilst offline only land is considered. Important parameters are listed in Tables 1 and 2, ancillaries in Table 3, and in most cases, switches are listed in the text. The full set of switch settings can be found in the Rose suites. We include the full parameter tables for the

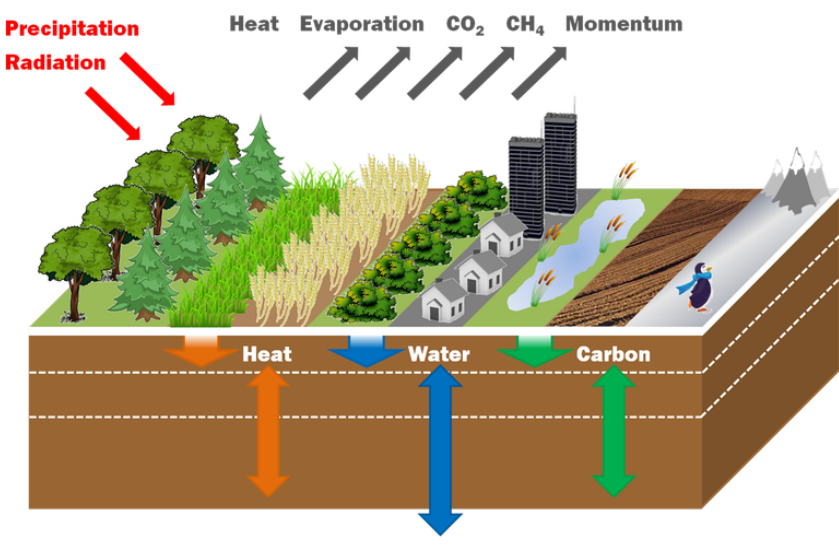

Figure 1. JULES schematic of the fluxes of stores of heat, water, carbon and momentum, and the surface tiling representation of subgrid heterogeneity.

surface tiles here for clarity as the Rose suite namelists encompass all parameters in JULES, many of which are linked to particular switches and options and therefore not used in JULES-GL7. Work is progressing to simplify the Rose suite namelists using existing tools within Rose to hide unused parameters and options. The appropriate JULES documentation papers remain Best et al. (2011) and Clark et al. (2011). Where new developments are included, they are described in more detail with appropriate references herein.

\subsection{Surface tiling}

JULES-GL7 uses a surface tiling scheme to represent subgrid heterogeneity. Within a grid box, each tile has its own surface energy budget and is coupled to a single shared soil column (Fig. 1). Each tile therefore has its own albedo, surface conductance to moisture, turbulent fluxes, ground heat flux, radiative fluxes, canopy water content, snow mass and melt, and thus surface temperature. Each tile requires its own parameter set which is given in Tables 1 (non-vegetated surface types) and 2 (vegetated surface types) and spatially explicit parameters in Table 3.

There are nine surface tiles consisting of five plant functional types (PFTs) (broadleaf trees, needleleaf trees, $\mathrm{C}_{3}$ grass, $\mathrm{C}_{4}$ grass and shrubs) and four non-vegetated surface types (urban, inland water, bare soil and ice) (Fig. 2). These can coexist in the same grid box except for ice. The $\mathrm{C}_{4}$ distinction reflects a different photosynthetic pathway with all other PFTs represented as $\mathrm{C}_{3}$. The tile fractions are spatially varying and are read from an ancillary file. The fractions are produced by a remapping of the 17 surface types in the IGBP (Loveland and Belward, 1997) to the nine surface types in JULES. The land cover class remapping procedure is described in Table 4 of Walters et al. (2019) and the crosswalking table relating land cover classes to PFTs in Table B1. 
Table 1. Parameters in JULES-GL7 that vary with non-vegetated surface types (note that these can be found in nvegparm).

\begin{tabular}{|c|c|c|c|c|}
\hline & Urban & Lake & Bare soil & Ice \\
\hline $\begin{array}{l}\text { albsnf } \\
\text { Snow-free albedo }\end{array}$ & 0.18 & 0.12 & -1 (indicates read from ancillary) & 0.75 \\
\hline $\begin{array}{l}\text { catch } \\
\text { Water capacity }\left(\mathrm{kg} \mathrm{m}^{-2}\right)\end{array}$ & 0.5 & 0 & 0 & 0 \\
\hline $\begin{array}{l}c h \\
\text { Heat capacity of this surface type }\left(\mathrm{JK}^{-1} \mathrm{~m}^{-2}\right)\end{array}$ & 280000 & 21100000 & 0 & 0 \\
\hline $\begin{array}{l}\text { emis } \\
\text { Surface emissivity }\end{array}$ & 0.97 & 0.985 & 0.9 & 0.99 \\
\hline $\begin{array}{l}g s \\
\text { Surface conductance }\left(\mathrm{m} \mathrm{s}^{-1}\right)\end{array}$ & 0 & 0 & 0.01 & 1000000 \\
\hline $\begin{array}{l}\text { infil } \\
\text { Infiltration enhancement factor }\end{array}$ & 0.1 & 0 & 0.5 & 0 \\
\hline $\begin{array}{l}v f \\
\text { Switch indicating whether the canopy is conductiv- } \\
\text { ity coupled (0) to the subsurface or radiatively (1) }\end{array}$ & 1 & 1 & 0 & 0 \\
\hline $\begin{array}{l}z 0 \\
\text { Roughness length for momentum (m) }\end{array}$ & 1 & 0.0001 & 0.001 & 0.0005 \\
\hline $\begin{array}{l}z O h m \\
\text { Ratio of the roughness length for heat to the rough- } \\
\text { ness length for momentum }\end{array}$ & $1 \times 10^{-7}$ & 0.25 & 0.02 & 0.2 \\
\hline
\end{tabular}

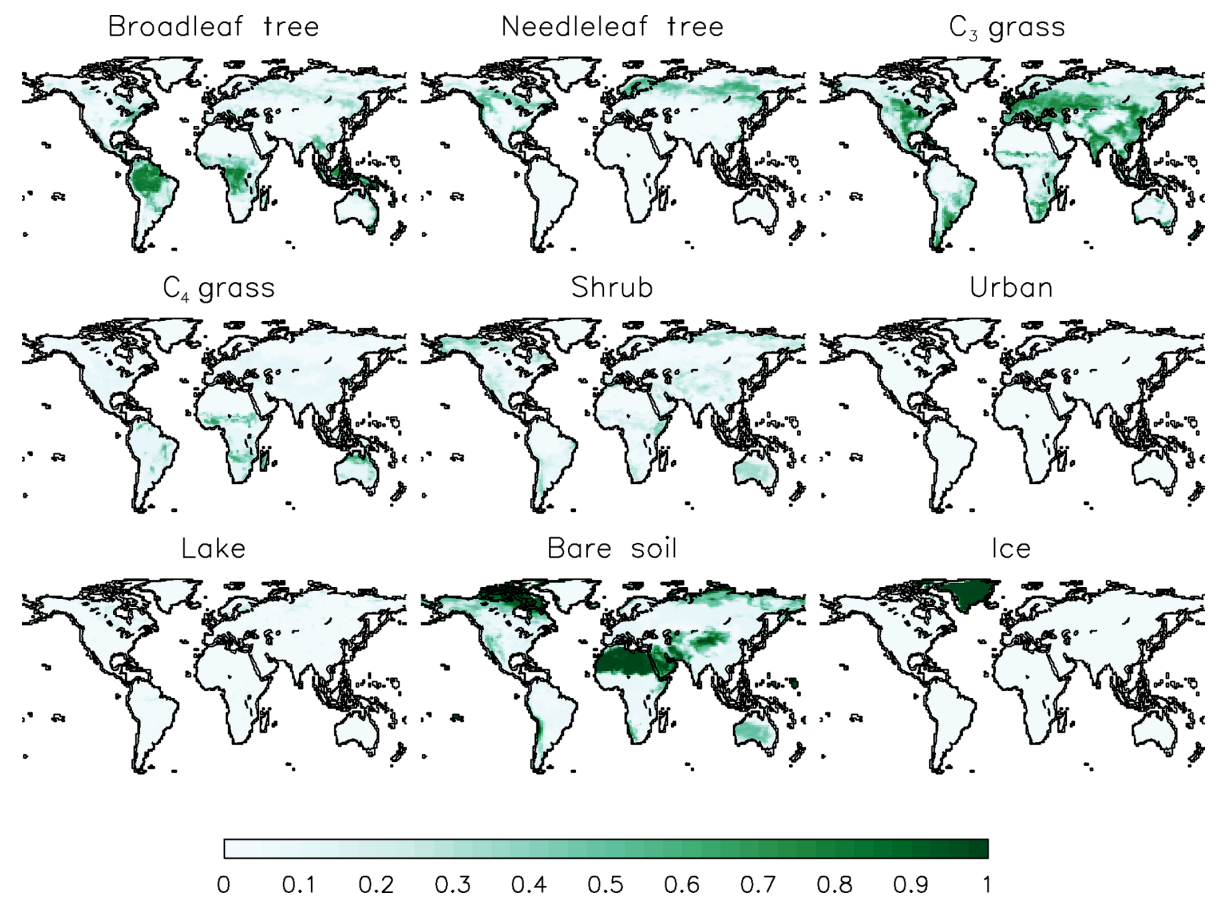

Figure 2. Surface tile fractions as used in JULES-GL7 derived from the IGBP land cover dataset (IGBP: Loveland et al., 2000). 
Table 2. Parameters in JULES-GL7 that vary by PFT (note that these can be found in pftparm and snow namelists).

\begin{tabular}{|c|c|c|c|c|c|}
\hline & Broadleaf tree & Needleleaf tree & $\mathrm{C}_{3}$ grass & $\mathrm{C}_{4}$ grass & Shrub \\
\hline $\begin{array}{l}a \_w l \\
\text { Allometric coefficient relating the target woody } \\
\text { biomass to the leaf area index }\end{array}$ & 0.65 & 0.65 & 0.005 & 0.005 & 0.1 \\
\hline $\begin{array}{l}\text { a_ws } \\
\text { Woody biomass as a multiple of live stem biomass }\end{array}$ & 10 & 10 & 1 & 1 & 10 \\
\hline $\begin{array}{l}\text { albsnc_max } \\
\text { Snow-covered albedo for large leaf area index }\end{array}$ & 0.25 & 0.25 & 0.6 & 0.6 & 0.4 \\
\hline $\begin{array}{l}\text { albsnc_min } \\
\text { Snow-covered albedo for zero leaf area index }\end{array}$ & 0.3 & 0.3 & 0.8 & 0.8 & 0.8 \\
\hline $\begin{array}{l}\text { alnir } \\
\text { Leaf reflection coefficient for NIR }\end{array}$ & 0.45 & 0.35 & 0.58 & 0.58 & 0.58 \\
\hline $\begin{array}{l}\text { alpar } \\
\text { Leaf reflection coefficient for PAR (photosyntheti- } \\
\text { cally active radiation) }\end{array}$ & 0.1 & 0.07 & 0.1 & 0.1 & 0.1 \\
\hline $\begin{array}{l}\text { alpha } \\
\text { Quantum efficiency }\left(\mathrm{mol} \mathrm{CO}_{2} \text { per mol PAR pho- }\right. \\
\text { tons) }\end{array}$ & 0.08 & 0.08 & 0.08 & 0.04 & 0.08 \\
\hline $\begin{array}{l}\text { b_wl } \\
\text { Allometric exponent relating the target woody } \\
\text { biomass to the leaf area index }\end{array}$ & 1.667 & 1.667 & 1.667 & 1.667 & 1.667 \\
\hline $\begin{array}{l}c 3 \\
\mathrm{C}_{3} / \mathrm{C}_{4} \text { photosynthetic pathway switch }\end{array}$ & 1 & 1 & 1 & 0 & 1 \\
\hline $\begin{array}{l}\text { can_struct_a } \\
\text { Canopy structure factor }\end{array}$ & 1 & 1 & 1 & 1 & 1 \\
\hline $\begin{array}{l}\text { catch0 } \\
\text { Minimum amount of water that can be held on the } \\
\text { canopy }\left(\mathrm{kg} \mathrm{m}^{-2}\right)\end{array}$ & 0.5 & 0.5 & 0.5 & 0.5 & 0.5 \\
\hline $\begin{array}{l}\text { dcatch_dlai } \\
\text { Rate of change of canopy capacity with LAI } \\
\left(\mathrm{kg} \mathrm{m}^{-2}\right)\end{array}$ & 0.05 & 0.05 & 0.05 & 0.05 & 0.05 \\
\hline $\begin{array}{l}\text { dqcrit } \\
\text { Critical humidity deficit }\left(\mathrm{kg} \mathrm{H}_{2} \mathrm{O} \text { per kg air) }\right.\end{array}$ & 0.09 & 0.06 & 0.1 & 0.075 & 0.1 \\
\hline $\begin{array}{l}d z O v \_d h \\
\text { Rate of change of vegetation roughness length for } \\
\text { momentum with height }\end{array}$ & 0.05 & 0.05 & 0.1 & 0.1 & 0.1 \\
\hline $\begin{array}{l}\text { emis_pft } \\
\text { Surface emissivity }\end{array}$ & 0.98 & 0.99 & 0.98 & 0.98 & 0.98 \\
\hline $\begin{array}{l}\text { eta_sl } \\
\text { Live stemwood coefficient }\left(\mathrm{kg} \mathrm{cm}^{-1} /\left(\mathrm{m}^{2} \text { leaf }\right)\right)\end{array}$ & 0.01 & 0.01 & 0.01 & 0.01 & 0.01 \\
\hline $\begin{array}{l}f 0 \\
\text { Ratio of internal to atmospheric } \mathrm{CO}_{2} \text { concentration } \\
\text { at } 0 \text {; humidity deficit }(\mathrm{CI} / \mathrm{CA} \text { for } \mathrm{DQ}=0)\end{array}$ & 0.875 & 0.875 & 0.9 & 0.8 & 0.9 \\
\hline $\begin{array}{l}f d \\
\text { Scale factor for dark respiration }\end{array}$ & 0.015 & 0.015 & 0.015 & 0.025 & 0.015 \\
\hline
\end{tabular}


Table 2. Continued.

\begin{tabular}{|c|c|c|c|c|c|}
\hline & Broadleaf tree & Needleleaf tree & $\mathrm{C}_{3}$ grass & $\mathrm{C}_{4}$ grass & Shrub \\
\hline $\begin{array}{l}f s m c \_ \text {mod } \\
\text { Switch for method of weighting the contribution that differ- } \\
\text { ent soil layers make to the soil moisture availability factor } \\
\text { fsmc }\end{array}$ & 0 & 0 & 0 & 0 & 0 \\
\hline $\begin{array}{l}\text { glmin } \\
\text { Minimum leaf conductance for } \mathrm{H}_{2} \mathrm{O}\left(\mathrm{m} \mathrm{s}^{-1}\right)\end{array}$ & 0.000001 & 0.000001 & 0.000001 & 0.000001 & 0.000001 \\
\hline $\begin{array}{l}\text { infil_f } \\
\text { Infiltration enhancement factor }\end{array}$ & 4 & 4 & 2 & 2 & 2 \\
\hline $\begin{array}{l}\text { kext } \\
\text { Light extinction coefficient }\end{array}$ & 0.5 & 0.5 & 0.5 & 0.5 & 0.5 \\
\hline $\begin{array}{l}k n l \\
\text { Parameter for decay of nitrogen through the canopy, as a } \\
\text { function of LAI }\end{array}$ & 0.2 & 0.2 & 0.2 & 0.2 & 0.2 \\
\hline $\begin{array}{l}\text { kpar } \\
\text { PAR extinction coefficient }\end{array}$ & 0.5 & 0.5 & 0.5 & 0.5 & 0.5 \\
\hline $\begin{array}{l}\text { lai_alb_lim } \\
\text { Minimum LAI permitted in calculation of the albedo in } \\
\text { snow-free conditions }\end{array}$ & 0.005 & 0.005 & 0.005 & 0.005 & 0.005 \\
\hline $\begin{array}{l}n l 0 \\
\text { Top leaf nitrogen concentration }(\mathrm{kg} \mathrm{N} / \mathrm{kg} \mathrm{C})\end{array}$ & 0.04 & 0.03 & 0.06 & 0.03 & 0.03 \\
\hline $\begin{array}{l}\text { neff } \\
\text { Scale factor relating vcmax with leaf nitrogen concentration }\end{array}$ & 0.0008 & 0.0008 & 0.0008 & 0.0004 & 0.0008 \\
\hline $\begin{array}{l}n r \_n l \\
\text { Ratio of root nitrogen concentration to leaf nitrogen con- } \\
\text { centration }\end{array}$ & 1 & 1 & 1 & 1 & 1 \\
\hline $\begin{array}{l}n s \_n l \\
\text { Ratio of stem nitrogen concentration to leaf nitrogen con- } \\
\text { centration }\end{array}$ & 0.1 & 0.1 & 1 & 1 & 0.1 \\
\hline $\begin{array}{l}\text { omega } \\
\text { Leaf scattering coefficient for PAR }\end{array}$ & 0.15 & 0.15 & 0.15 & 0.17 & 0.15 \\
\hline $\begin{array}{l}\text { omnir } \\
\text { Leaf scattering coefficient for NIR }\end{array}$ & 0.7 & 0.45 & 0.83 & 0.83 & 0.83 \\
\hline $\begin{array}{l}\text { orient } \\
\text { Parameter specifying the angular distribution of leaf orien- } \\
\text { tations }\end{array}$ & 0 & 0 & 0 & 0 & 0 \\
\hline $\begin{array}{l}q 10_{\_} \text {leaf } \\
Q_{10} \text { factor for plant respiration }\end{array}$ & 2 & 2 & 2 & 2 & 2 \\
\hline $\begin{array}{l}r \_g r o w \\
\text { Growth respiration fraction }\end{array}$ & 0.25 & 0.25 & 0.25 & 0.25 & 0.25 \\
\hline $\begin{array}{l}\text { rootd_ft } \\
\text { Parameter determining the root depth }(\mathrm{m})\end{array}$ & 3 & 1 & 0.5 & 0.5 & 0.5 \\
\hline $\begin{array}{l}\text { sigl } \\
\text { Specific density of leaf carbon }\left(\mathrm{kg} \mathrm{C} \mathrm{m}^{-2} \text { leaf }\right)\end{array}$ & 0.0375 & 0.1 & 0.025 & 0.05 & 0.05 \\
\hline $\begin{array}{l}\text { Tlow } \\
\text { Lower temperature for photosynthesis }\left({ }^{\circ} \mathrm{C}\right)\end{array}$ & 0 & -5 & 0 & 13 & 0 \\
\hline
\end{tabular}


Table 2. Continued.

\begin{tabular}{|c|c|c|c|c|c|}
\hline & Broadleaf tree & Needleleaf tree & $\mathrm{C}_{3}$ grass & $\mathrm{C}_{4}$ grass & Shrub \\
\hline $\begin{array}{l}\text { Tupp } \\
\text { Upper temperature for photosynthesis }\left({ }^{\circ} \mathrm{C}\right)\end{array}$ & 36 & 31 & 36 & 45 & 36 \\
\hline $\begin{array}{l}z O h m \_p f t \\
\text { Ratio of the roughness length for heat to the rough- } \\
\text { ness length for momentum }\end{array}$ & 1.65 & 1.65 & 0.1 & 0.1 & 0.1 \\
\hline Snow parameters & & & & & \\
\hline $\begin{array}{l}\text { can_clump } \\
\text { Clumping factor for snow in the canopy }\end{array}$ & 1 & 4 & 1 & 1 & 1 \\
\hline $\begin{array}{l}\text { cansnowpft } \\
\text { Canopy snow model switch }\end{array}$ & false. & true. & false. & false. & false \\
\hline $\begin{array}{l}\text { lai_alb_lim_sn } \\
\text { Lower limit on permitted LAI in albedo with snow }\end{array}$ & 1 & 1 & 0.1 & 0.1 & 0.1 \\
\hline $\begin{array}{l}\text { n_lai_exposed } \\
\text { Shape parameter for exposed canopy with embed- } \\
\text { ded snow }\end{array}$ & 1 & 1 & 3 & 3 & 2 \\
\hline $\begin{array}{l}\text { unload_rate_cnst } \\
\text { Constant canopy snow unloading rate }\left(\mathrm{kg} \mathrm{m}^{-2} \mathrm{~s}^{-1}\right)\end{array}$ & 0 & 0 & 0 & 0 & 0 \\
\hline $\begin{array}{l}\text { unload_rate_u } \\
\text { Wind-dependent canopy snow unloading rate } \\
\left(\mathrm{kg} \mathrm{m}^{-2} \mathrm{~s}^{-1}\left(\mathrm{~m} \mathrm{~s}^{-1}\right)^{-1} \text { wind }\right)\end{array}$ & 0 & $2.31 \times 10^{-6}$ & 0 & 0 & 0 \\
\hline
\end{tabular}

\subsubsection{Plant functional types (PFTs)}

Vegetation is represented by the five plant functional types described above. In JULES-GL7, each PFT has its own energy budget including thermal heat capacity (CanMod= 4), which is a function of the PFT height (Sects. "Spatial leaf area and canopy height ancillary data" and 2.3). Leaflevel stomatal conductance and photosynthesis are coupled through $\mathrm{CO}_{2}$ diffusion with PFT-specific parameters controlling sensitivity to humidity deficit and internal to external $\mathrm{CO}_{2}$ pressures (Cox et al., 1998 and Table 2; f0, dqcrit). This coupling implies that both the energy and carbon cycles are closely related; rising atmospheric $\mathrm{CO}_{2}$ influences stomatal conductance and therefore the surface energy budget. This mechanism is known as physiological forcing (Betts et al., 2007; Field et al., 1995; Sellers et al., 1996). Leaflevel conductance must be scaled to the canopy level, and in JULES-GL7 this is done using a 10-layer canopy approach $($ CanRadMod=4). At each level, separate direct and diffuse photosynthetically available radiation (PAR) levels are calculated using the two-stream approach (Sellars, 1985) to give a profile of PAR through the canopy. From this, the leaf-level photosynthesis can be calculated using PFT-specific parameters combined with the Collatz et al. $(1992,1991)$ leaf biochemistry model utilising separate mechanisms for $\mathrm{C}_{3}$ and $\mathrm{C}_{4}$ plants (Jogireddy et al., 2006; Mercado et al., 2007). At each level, if net photosynthesis is negative or stomatal con- ductance is below a minimal threshold (glmin; Table 1), the stomata are closed and the stomatal conductance is set to this minimum. A further mechanism scales leaf-level conductance via photosynthesis according to the availability of soil moisture in the rooting profile. In JULES-GL7, this scalar $(\beta)$ relates the rooting profile (rootd; Table 2 ) in each soil layer with the availability of soil moisture. $\beta$ is a piecewise function that scales from 0 when soil moisture is at or below the wilting point to 1 where soil moisture is above the critical point (Eq. 12; Best et al., 2011). The root fraction weighted $\left(f s m c \_m o d=0\right)$ total across soil layers value of $\beta$ is used to scale photosynthesis at the leaf level. Canopy conductance is the leaf area weighted sum of leaf conductance across the 10 levels. A direct output from this setup is a diagnostic of gross primary productivity (GPP). However, as this is the non-biogeochemical configuration, the fixed GPP does alter the canopy structure.

\section{Spatial leaf area and canopy height ancillary data}

Leaf area index (LAI) is defined as the one-sided surface area of canopy leaf cover per unit area of land and is defined spatially and temporally for each vegetated surface tile in JULES-GL7. Similarly, canopy height is spatially varying per vegetated tile but fixed in time. The ancillaries are derived from satellite data processed to be consistent with the land cover and plant functional type classifications used 
Table 3. Ancillary information as required in the JULES-GL7.0/7.2 configurations. Required ancillary files cover parameter values that are either spatially or temporarily explicitly necessary to define the science configuration. Additional ancillaries covering grid setup and forcing are used in the experimental setup.

\begin{tabular}{ll}
\hline File & Fields and description \\
\hline Science configuration & \\
\hline Land cover fractions & frac: spatial fractional cover of each land cover tile \\
\hline Vegetation function & canht: canopy height for vegetation tiles \\
\cline { 2 - 2 } & lai: monthly leaf area index climatology for vegetation tiles \\
\hline Soil properties & $\begin{array}{l}\text { albsoil: average waveband spatial field } \\
\text { b: van Genuchten soil hydraulic parameter }(1 /(n-1)) \\
\text { hcap: dry heat capacity } \\
\text { satcon: saturated hydraulic conductivity } \\
\text { sathh: van Genuchten soil hydraulic 1/alpha parameter } \\
\text { smcrit: volumetric soil moisture critical point } \\
\text { smsat: saturated volumetric soil moisture } \\
\text { smwilt: volumetric soil moisture wilting point }\end{array}$ \\
\hline Hydrology & $\begin{array}{l}\text { timean: spatial mean in topographic index } \\
\text { tisig: spatial standard deviation in topographic index }\end{array}$ \\
\hline Experimental setup & \\
\hline Land fraction & Land_frac: fraction of a grid box that is land \\
\hline
\end{tabular}

in JULES-GL7. To do this requires decomposing a "mixed" signal from the satellite data into individual PFT contributions. This is achieved via an additional parameter, the "balanced" LAI (Lb), meaning the LAI that would be reached if the plant was in full leaf (Table B2). The combination of the mapping from land cover classes to PFTs and the balanced LAI weighting per PFT per land cover class allows the observed gridded satellite value to be decomposed into individual PFT contributions.

In JULES-GL7, monthly variations in LAI about the balanced LAI are based on a climatology for the period 2005 to 2009 derived from the MODIS LAI product (MOD15; Yang et al., 2006). The LAI value for a given PFT, land cover class and month are calculated as follows:

$\operatorname{LAI}_{i, j}=\operatorname{LAI}_{\text {MODIS }} \frac{\left(\mathrm{Lb}_{i, j} \alpha_{i, j}\right)}{\sum_{i}\left(\operatorname{Lb}_{i, j} \alpha_{i, j}\right)}$,

where $\mathrm{LAI}_{i}$ is the LAI for PFT class $i, \mathrm{LAI}_{\text {MODIS }}$ is the MODIS LAI value for a given month, $\mathrm{Lb}_{i, j}$ is given by the LAI lookup table (Table B2), $\alpha_{i, j}$ is the fraction of each PFT $i$ in IGBP class $j$ given by the lookup table in Table B1. The PFT-specific LAI $\left(\mathrm{LAI}_{i}\right)$ is accumulated for all land cover classes in a grid box for a given month. The resulting input ancillary is then internally interpolated within JULES to each model time step. The seasonally varying LAI for five PFTs for $30-60^{\circ} \mathrm{N}$ is shown in Fig. 3. An outcome of this approach is that JULES is forced with the snow-free LAI, which explains the large winter reductions in LAI for needleleaf trees.

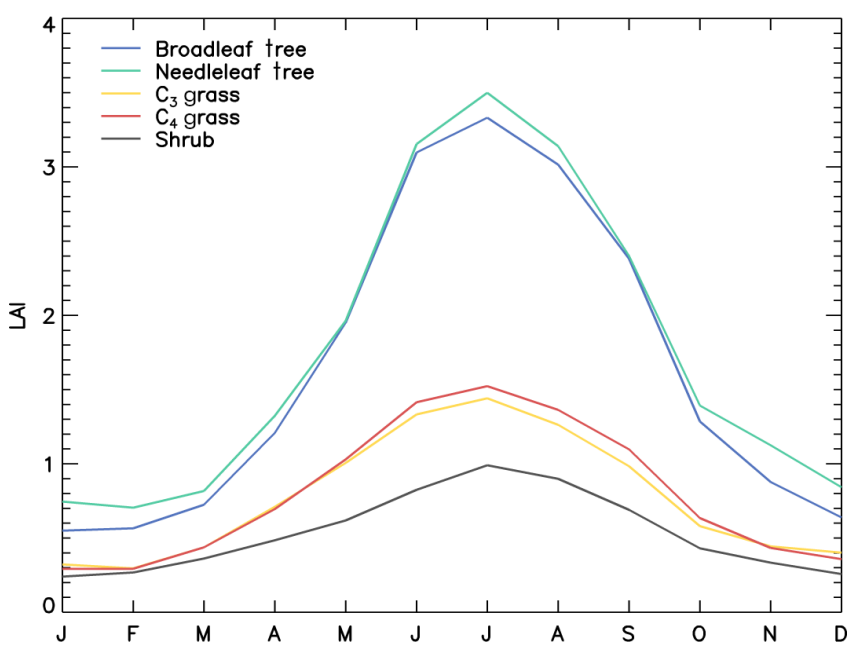

Figure 3. Seasonal LAI for the five vegetation surface types, area averaged over $30-60^{\circ} \mathrm{N}$.

Improving the treatment of LAI in the ancillary information is a priority development for future versions of GL.

The introduced balanced LAI has the property of being allometrically related to the canopy height. Based on this allometric relationship, the canopy height $(H)$ can be derived for each PFT in each land cover class (Jones, 1998):

$H_{i, j}=h_{i} \mathrm{Lb}_{i, j}^{\frac{2}{3}}$, 
where $h_{i}$ is a PFT-specific scalar given in Appendix B (Table B3). The PFT cover mean height (canht) is the areaweighted arithmetic mean of the land cover classes in that grid box. Canopy height (Fig. 4) is therefore based on allometric scaling of land-cover-class-dependent parameters. Improving the representation of canopy height is also a priority area for future developments.

\subsubsection{Non-vegetated surface types}

The four non-vegetated surface types (urban, inland water, bare soil and land ice) like the vegetated surface types are represented as tiles with separate energy balances, described using the parameters listed in Table 1. A full description of the representation of the non-vegetated surface types can be found in Best et al. (2011), and the developments after this paper have been highlighted here. After GL3.0 (Walters et al., 2011), the urban surface has been represented by the simple one-tile scheme ( $l$ urban $2 t=$.false. $)$, which consists of a radiatively coupled ( $v f$; Table 1$)$ "urban canopy" with the thermal characteristics (ch; Table 1) of concrete (Best, 2005). The urban canopy has a capacity to hold water (catch; Table 1), and when wet, the surface moisture resistance is reduced to zero. Similar to the urban surface, lakes are represented as a radiatively coupled "inland water canopy" with the thermal characteristics of a mixed layer depth of water $(\approx 5 \mathrm{~m})$. The original representation of inland water, as a freely evaporating soil surface $(c h=v f=0.0$; Table 1$)$, was shown to have incorrect seasonal and diurnal cycles for surface temperatures and therefore evaporation (Rooney and Jones, 2010). The high thermal inertia of the urban and lake tiles results in an improved diurnal cycle in surface air temperature. Bare soil or bare-ground surface types are represented as having no canopy heat capacity and a surface moisture resistance to evaporation as a function of surface soil moisture (Eq. 17, Best et al., 2011). Ice surfaces are an exception to the representation of surface heterogeneity, as only ice can exist in a grid box. This is because the subsurface is modified to represent the thermal characteristics of ice. No infiltration is allowed, and all melt is assumed to be surface runoff. The surface temperature is limited to the melting point with the residual energy balance term assumed to be melt. As such, ice surfaces do not conserve water.

The roughness lengths for inland water, bare soil and ice were updated to their current values as part of GL4.0 (Walters et al., 2014). The roughness length ( $z 0$; Table 1) for inland water was reduced to $1 \times 10^{-4} \mathrm{~m}$, as GL3.0 suffered from a slow bias when compared to reanalyses in the near-surface wind speed around the Great Lakes. This reduced value is more consistent with the values predicted from wind-speeddependent parameterisations over open water (Walters et al., 2014). The roughness length for bare soil was increased to $1 \times 10^{-3} \mathrm{~m}$, an intermediate value between those used in GL3.0 $\left(3 \times 10^{-4} \mathrm{~m}\right)$ and GL3.1 $\left(3.2 \times 10^{-3} \mathrm{~m}\right.$, used in operational global NWP forecasting). Observational estimates of the roughness length of bare soil surfaces suggest large geographical variations covering this range. The ratios of the roughness lengths for heat to momentum (zOhm; Table 1) were also revised as part of GL4.0 in conjunction with the roughness length changes. From GL4.0, the urban surface has used the Best (2006) value of $1 \times 10^{-7} \mathrm{~m}$; for inland water, the ratio has been set to 0.25 , consistent with the parameterisation for open sea; bare soil was decreased to 0.02 to address a significant underestimate of the near-surface temperature gradient over arid regions; and ice was adjusted to 0.2 to be consistent with sea ice. Prior to GL4.0, all ratios had a fixed value of 0.1 . Another new capability introduced with GL4.0 was an emissivity for each surface type (emis; Table 1) based on the data of Snyder et al. (1998) and additionally for bare soil, satellite retrievals of land surface temperature from over the Sahara. Previously, these values were fixed at 0.97 regardless of surface type. The significant reduction in the bare soil emissivity improved a cold bias over the Middle Eastern deserts that was prominent in GL3.0. The description of the non-vegetated surface types in JULES-GL7 remains largely unchanged since GL4.0 (Best et al., 2011).

\subsection{Radiation}

Typically, stand-alone JULES is driven with downward shortwave and longwave radiative fluxes. To obtain the net fluxes that enter the surface energy budget, the surface albedo and emissivity must be calculated. The albedo varies with wavelength, although, for many natural surfaces, it is adequate to distinguish between the visible and near-infrared parts of the spectrum. In reality, the albedo is also different for direct and diffuse radiation, but a distinction is not made for every surface in GL7.

For unvegetated surfaces, single broadband albedos are used (albsnf; Table 1). The albedo of bare soil must be specified as ancillary data, but fixed values are used for the other three unvegetated tiles.

The albedo of plant canopies is calculated using the twostream radiation scheme described by Sellers (1985). As input, this requires separate transmission (omega, omnir; Table 2) and reflection coefficients (alpar, alnir; Table 2) in the visible and near-infrared regions, respectively, for individual leaves (or shoots in the case of needleleaf trees) and the leaf area index. It returns the visible and near-infrared albedos for direct and diffuse radiation. However, the direct components are discarded and not used in GL7 for reasons of performance when coupled to the UM. When coupled to the UM, there is an option ( $l$ albedo_obs) to scale the leaf-level characteristics to match a specified climatology of the albedo, but this is unavailable offline.

A new albedo scheme for snow-covered surfaces was introduced into GL7. This incorporates a two-stream algorithm for the snowpack. The surface is modelled as an underlying soil surface, above which there is a plant canopy that is gradually buried as snow accumulates. The canopy is therefore 

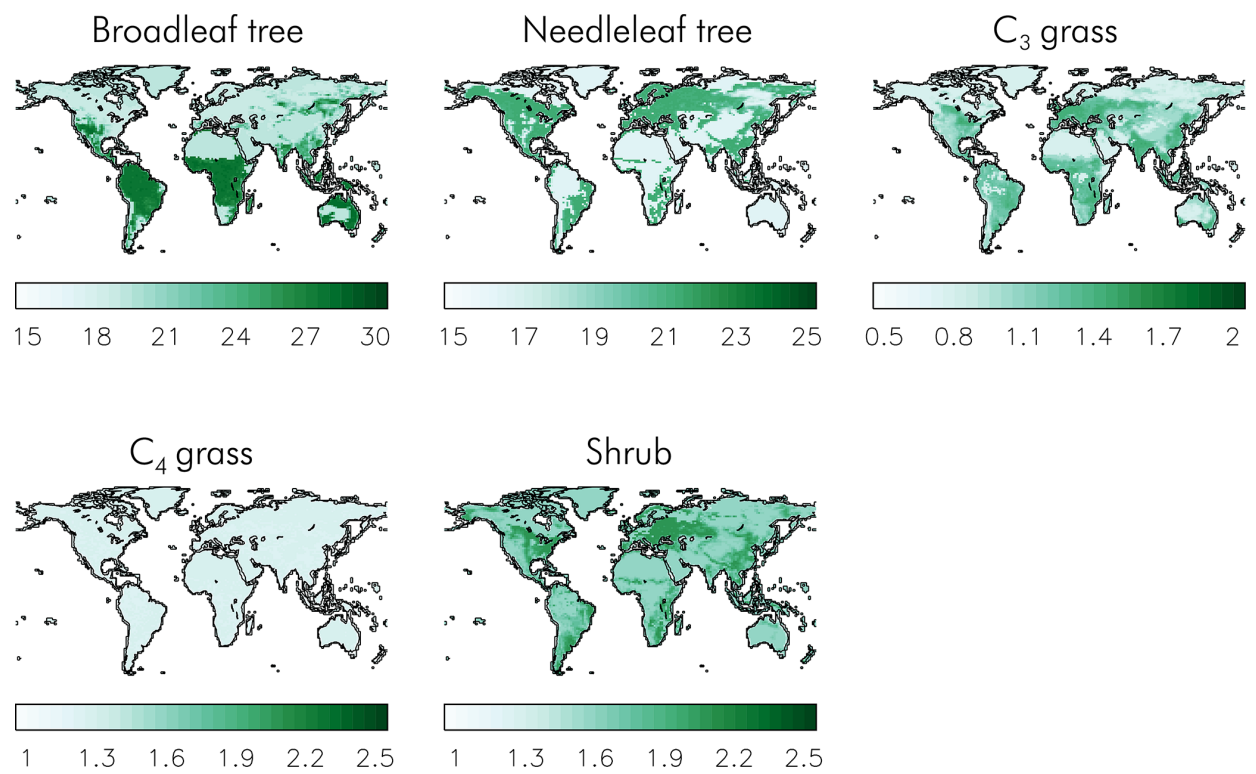

Figure 4. Canopy height $(\mathrm{m})$ per PFT, as used in JULES-GL7, derived from the IGBP land cover dataset (IGBP: Global Soil Data Task, 2000).

modelled as a lower snow layer and an upper layer of exposed vegetation that will be absent if the snow is deep enough. The scheme makes explicit use of the canopy height. If canopy snow is allowed on the tile, there will also be a layer of snow on the canopy that is treated using the same two-stream scheme. Additional parameters (can_clump, n_lai_exposed) represent the vertical distribution of leaf area density and the clumping of snow on the canopy. However, the values adopted in GL7 have been tuned to work with the existing ancillaries of canopy height which exhibit unrealistically limited spatial variability. Previously, a hard-wired lower limit of 0.5 had been imposed on the LAI in the calculation of the albedo. In GL7, this has been removed and replaced with separate limits for snow and snow-free conditions. In snow-free conditions, the nominal lower limit has been set to 0.005 , while in the presence of snow a limit of 1.0 is imposed for trees and a limit of 0.1 in the case of short vegetation (Table 2). Infrared emissivities are specified as single broadband values for each surface type (Tables 1 and 2).

\subsubsection{Diffuse radiation}

GL7 assumes that PAR is half of the total downwelling shortwave. The PAR as seen in the plant physiology is entirely direct, which results in a lower penetration of PAR into the canopy and reduced photosynthesis at the subcanopy level. For GL7.2, we introduce a constant global mean diffuse fraction of 0.4 , based on output from the SOCRATES radiative transfer scheme (Edwards and Slingo, 1996; Manners et al., 2018). This has the impact of increasing light penetration into the canopy and therefore increasing GPP. To further improve GPP, we updated the canopy radiation model (can_rad_mod, changed from 4 to 6). Like can_rad_mod $=5,6$ introduces sunfleck penetration through the canopy (fsun $=\exp \left(-\frac{k_{b}}{\cos z} \mathrm{LAI}\right) ; k_{b}$ constant value of 0.5$)$ which increases the light within the canopy particularly for high solar zenith angles. Furthermore, can_rad_mod= 6 introduces a new nitrogen profile through the canopy following $\exp \left(-k_{n l} \mathrm{LAI}\right.$ ), where $k_{n l}$ is a PFT constant of 0.2 (Table 2). This has the effect of increasing potential GPP in canopies with low $\operatorname{LAI}(<5)$ and decreasing at high LAI $(>5)$. GL7.2 is consequently a physically more realistic configuration of JULES. The changes to canopy radiation do not affect the simulated albedo, as in the current setup the albedo is only calculated for direct radiation. GL7.0 and 7.2 will therefore have the same albedo, but the way light interacts with the canopy differs and therefore affects the exchange of moisture and carbon.

\subsection{Surface exchange}

The representation of the surface energy budget in JULES is described by Best et al. (2011). The scheme includes a surface heat capacity. Atmospheric resistances are calculated using standard Monin-Obukhov surface layer similarity theory, using the stability functions of Beljaars and Holtslag (1991). Evaporation from bare soil and water on the canopy and transpiration through the plant canopy contribute to the latent heat fluxes. In the case of needleleaf trees, snow on and beneath the canopy is treated separately $($ can_mod $=4)$. 


\subsection{Soil hydrology and thermodynamics}

Soil processes are represented using a four-layer scheme for the heat and water fluxes with hydraulic relationships taken from Van Genuchten (1980). The four layers $(0.1,0.25,0.65$ and $2 \mathrm{~m}$ ) are chosen to capture diurnal, seasonal and multiannual variability in soil moisture and heat fluxes. The JULESGL7 soil parameter values are based in part on those developed for the MOSES model by Dharssi et al. (2009) and Cox et al. (1999), and are read from an ancillary. There is an additional deep layer with impeded drainage to represent shallow groundwater, thus enabling a saturated zone and water table to form. The subgrid-scale soil moisture heterogeneity model is driven by the statistical distribution of topography within the grid box and is based on a TOPMODEL-type approach (Gedney and Cox, 2003). The baseflow out of the model is dependent on the predicted grid box mean water table, while surface saturation and wetland fractions are dependent on the distribution of water table depth within the grid box. The scheme uses the Marthews et al. (2015) topographic index dataset at 15 arcsec resolution, which in turn is derived from HydroSHEDS (Lehner et al., 2006). The soil and hydrological ancillaries required are listed in Table 3.

\subsection{Snow}

A major difference between GL7 and earlier GL configurations is the activation of the multilayer snow scheme in JULES that is described by Best et al. (2011). This replaces the previous so-called zero-layer scheme in which a single thermal store was used for snow and the first soil level, and an insulating factor was applied to represent the lower thermal conductivity of snow. The zero-layer scheme included no representation of the evolution of the snowpack. Compared to the version described in Best et al. (2011), a number of enhancements have been introduced into the multilayer scheme in order to better to represent the thermal state of the snow surface and atmospheric boundary layer when coupled to the $\mathrm{UM}$. The changes are noted in the following description and parameter values in Table 2 .

In the multilayer scheme, the snowpack is divided into a number of layers that are added or removed as the snowpack grows or shrinks. A maximum of three layers is imposed in GL7. In a deep snowpack, the top layer will be $0.04 \mathrm{~m}$ thick, the second $0.12 \mathrm{~m}$ thick, while the lowest layer will contain the remainder of the snowpack. Very thin layers of snow (less than $0.04 \mathrm{~m}$ deep) are still represented using the zero-layer scheme for reasons of numerical stability. The thickness, frozen and liquid water contents, temperature and grain size of each layer are prognostics of the scheme. New snow is added to the top of the snowpack and compaction by the overburden is included. Following these operations, the snowpack is relayered to the specified thickness.

The density of fresh snow has been set to $109 \mathrm{~kg} \mathrm{~m}^{-2}$, following the scheme adopted in the CROCUS model (Vionnet

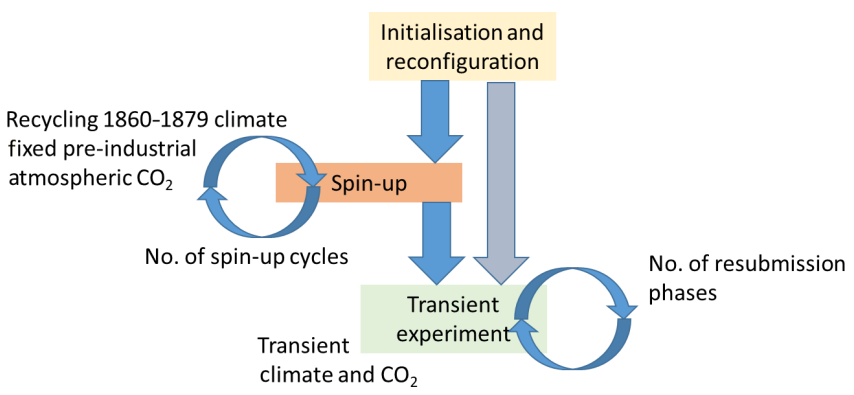

Figure 5. Suite control used to initialise, spin up and perform a full transient experiment with JULES-GL7.

et al., 2012), but omitting the wind speed and temperaturedependent factors. The conductivity of snow was originally calculated using the parameterisation of Yen (1981), but this has been replaced with the scheme proposed by Calonne et al. (2011). This gives higher conductivities in snow of low density, thereby strengthening the coupling between the snowpack and the boundary layer.

Again, with a view towards improving the coupling between the atmosphere and the snowpack, the parameterisation of equi-temperature metamorphism described by Dutra et al. (2010) has been introduced. This accelerates the rate of densification of fresh snow and is important in reducing cold biases that would otherwise result.

In the original scheme, when the canopy snow model was selected, unloading of snow from the canopy occurred only when it was melting. In GL7, unloading (unload_rate_u; Table 2) is also permitted at colder temperatures, and the timescale is set to $1 /($ unload_rate_u $*$ wind velocity at $10 \mathrm{~m})$, which is tuned to give an unloading timescale of $2 \mathrm{~d}$ in the Canadian boreal forest in winter (MacKay and Bartlett, 2006) for the average $10 \mathrm{~m}$ wind speed predicted in the UM. Note that a separate canopy is currently used only for the needleleaf tile.

Unlike the original scheme, where it simply bypassed the snowpack, rainwater is now allowed to infiltrate. Below a canopy, this infiltrating water includes melting from the canopy.

\subsection{Coupled versus uncoupled differences}

JULES has been developed in more than one modelling environment, i.e. stand-alone and coupled with the UM, and consequently some science options are not available under all environments. This could be because certain science options only make sense in a coupled environment or the converse may be true. This is not true for all options and in some cases the options have only been implemented in one environment and require additional coding to make it available to others. Other differences arise out of the method of coupling the available driving data. When coupled, the surface meteorological state is solved interactively, whereas offline 
this is provided either from observation or reanalysis products. One important difference concerning the treatment of radiation (jules_radiation) is that when coupled separate radiative fluxes of NIR and PAR are available from the radiation scheme, offline, typically only broadband shortwave is available, and it is assumed this can be split $50: 50$ between NIR and PAR. Furthermore, when coupled, snow-free albedos on each surface type are nudged towards an observed climatological mean from an ancillary ( $l \_a l b e d o \_o b s=$.true.). This approach maintains sensible differences between surface types and allows spatial differences in albedo properties to be captured, while agreeing well with observations. However, in turn, this has some limitations and as such it is not suitable for climate change experiments that include a change in land cover. It is therefore not compatible with the dynamic vegetation and land-use models as those used in the interactive carbon cycle option and thus is not implemented in the offline JULES-GL7 configuration. Another subtle difference concerning the treatment of radiation is the calculation of the solar zenith angle. When coupled, the SOCRATES radiative transfer scheme calculates this, whereas in stand-alone JULES, the solar zenith angle calculation needs to be explicitly turned on using $l_{-} \cos z=$.true. to be equivalent. When using JULES-GL7 therefore with site data, care should be taken to ensure that the model and forcing data are in Coordinated Universal Time (UTC), as time is used in the calculation of solar zenith angle.

There are several differences in the treatment of the JULES surface exchange (jules_surface), as this is the interface between the surface and either the driving model or the driving data. Orographic form drag (formdrag $=0$ standalone, 1 coupled), for example, cannot be used in the standalone configuration, as the necessary ancillary data are not available to stand alone. In any case, it may not make scientific sense to include this, as the orographic drag may be implicit in the driving data either from observations or from model-generated driving data. The method of discretisation in the surface layer is another difference between the two environments which affects how the driving data are interpreted. The driving data, when in standalone configuration, are most likely to be at a specific level $\left(i \_\right.$modiscopt $\left.=0\right)$ rather than a vertical average as they are when coupled ( $i$ modiscopt $=1$ ). Also in the coupled model, a parameterisation of transitional decoupling in very light winds is included in the calculation of the $1.5 \mathrm{~m}$ temperature (iscrntdiag $=2$ ); however, in stand-alone configuration, the surface is driven by the temperature at $1.5 \mathrm{~m}$ and is therefore not a diagnostic. It is not recommended that the surface is driven with a decoupled variable, as this scenario has not been properly tested and should instead be iscrntdiag $=0$. Finally, concerning the surface exchange, the coupled model includes the effects of both boundary layer and deep convective gustiness (isrfexcnvgust $=1$ ); however, this is not appropriate in stand-alone mode, and therefore isrfexc$n v g u s t=0$. When driving stand-alone JULES with observa-
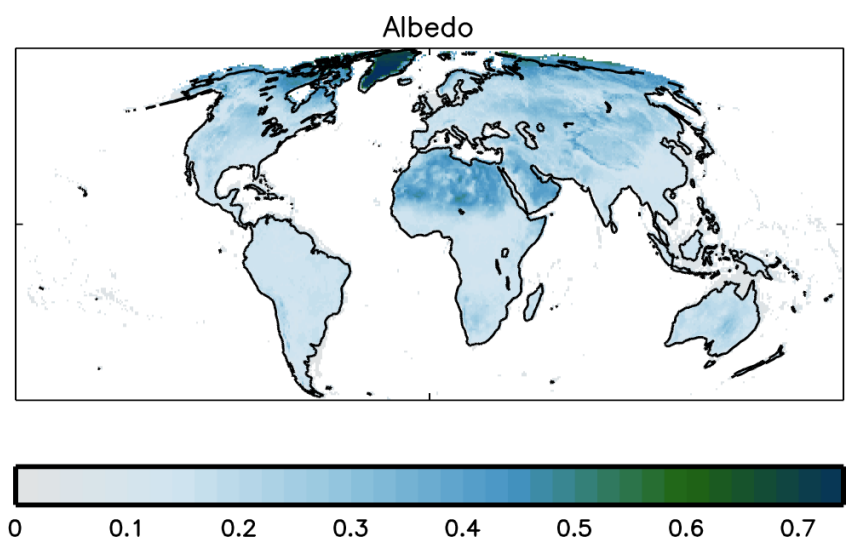

Figure 6. Surface albedo 2000-2005 benchmark derived from MODIS (De Kauwe et al., 2011), as generated by ILAMB (Collier et al., 2018).

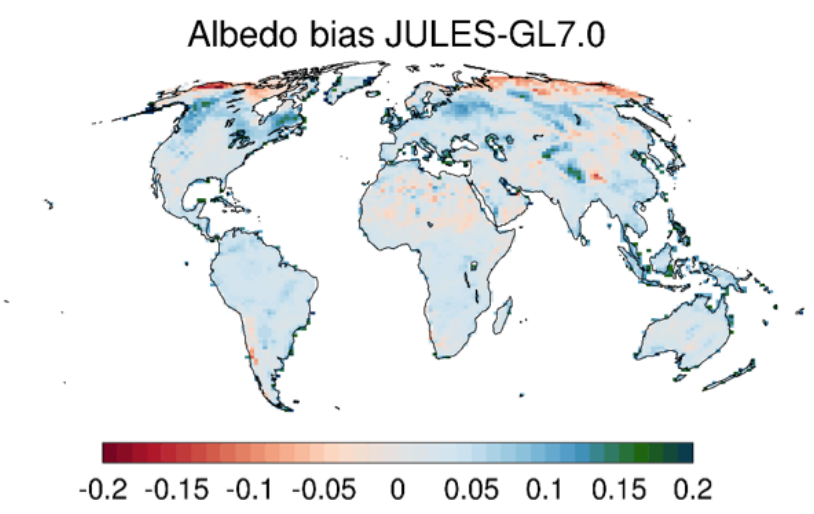

Figure 7. Albedo bias simulated by GL7.0 relative to the MODIS benchmark. Means over 2000-2005 are shown. Biases are calculated as the difference between the model and observations.

tions at a high-enough frequency, the gusts would be implicit in the observational data; and in the case of driving JULES with a longer-term average, where there may be a gust contribution, the relevant information is not accessible.

\section{JULES-GL7 experimental setup and suite control}

The science configuration consists of a defined set of parameters and switches that can be used in conjunction with an experimental setup. The experimental setup differs from the configuration, as it describes the conditions under which the configuration is applied. For example, in this case, the setup is a global historical experiment, but it could also be a future climate scenario, driven by alternative historical forcing or at multiple locations, such as FLUXNET sites, where more detailed evaluation data are available (e.g. Harper et al., 2016). The experiment in the suite provided is a global historical run from pre-industrial (1860) to the present day (2014) including rising atmospheric $\mathrm{CO}_{2}$ but fixed land cover. This is a standard historical experimental setup as used in the 
Table 4. Tabulated measures of model performance against benchmarks. Global means and totals are calculated on the native grid of the observational and model grids accounting for fractional land coverage in the totals and weighting for irregular grid box sizes. Biases and root mean square errors (RMSEs) are calculated by regridding the observational data to the coarser model grid and calculating metrics where the observational and model data intersect.

\begin{tabular}{|c|c|c|c|}
\hline & Global means/totals & Bias & RMSE \\
\hline \multicolumn{4}{|c|}{ MODIS albedo (dimensionless) } \\
\hline Benchmark & 0.20 & & \\
\hline GL7.0 & 0.25 & 0.039 & 0.074 \\
\hline \multicolumn{4}{|c|}{ GLEAM evapotranspiration $\left(\mathrm{mm} \mathrm{d}^{-1}\right)$} \\
\hline Benchmark & 1.29 & & \\
\hline GL7.0 & 1.72 & 0.35 & 0.65 \\
\hline GL7.2 & 1.70 & 0.33 & 0.62 \\
\hline \multicolumn{4}{|c|}{ MODIS evapotranspiration $\left(\mathrm{mm} \mathrm{d}^{-1}\right)$} \\
\hline Benchmark & 1.57 & & \\
\hline GL7.0 & 1.73 & 0.38 & 0.63 \\
\hline GL7.2 & 1.71 & 0.36 & 0.62 \\
\hline \multicolumn{4}{|c|}{ FLUXNET-MTE gross primary productivity $\left(\mathrm{gC} \mathrm{m}^{-2} \mathrm{~d}^{-1}\right)$} \\
\hline Benchmark & $119 \mathrm{GtC}$ & & \\
\hline GL7.0 & $91.1 \mathrm{GtC}$ & -0.6 & 1.06 \\
\hline GL7.2 & $95.4 \mathrm{GtC}$ & -0.5 & 0.99 \\
\hline
\end{tabular}

Global Carbon Project (Le Quéré et al., 2015). The climate data (Climate Research Unit - National Centers for Environmental Prediction; CRU-NCEP v7) consist of 6-hourly NCEP data corrected to CRU climatology and observations updated to 2014 (CRU TS3.23; Harris et al., 2014). The original data were provided on a $0.5^{\circ} \times 0.5^{\circ}$ grid and subsequently regridded to a coarser resolution for consistency with the standard resolution climate experiments for CMIP6 using HadGEM3-GC3.1 at $1.875^{\circ} \times 1.25^{\circ}$. The forcing data include both gridded observations of climate and global atmospheric $\mathrm{CO}_{2}$, which change over time (Dlugokencky and Tans, 2015). However, the CRU-NCEP data only start in 1901. To begin the experiments in 1860 , a time when atmospheric $\mathrm{CO}_{2}$ was relatively stable, requires the years $1901-$ 1920 to be replicated between 1860 and 1900 , thus assuming no effect of climate change between 1860 and 1901. CRUNCEP uses a $365 \mathrm{~d}$ calendar, so no leap years are included. Furthermore, CRU-NCEP is a land-only dataset including Greenland but excluding Antarctica. At the coarser resolution, a grid box may only be partially land covered. JULES works on the land-only fraction of the grid box. It is therefore important when making global means or averages that both the land fraction of a grid box as well as the grid box area are considered. An important provided ancillary is therefore the land fraction (Table 3).
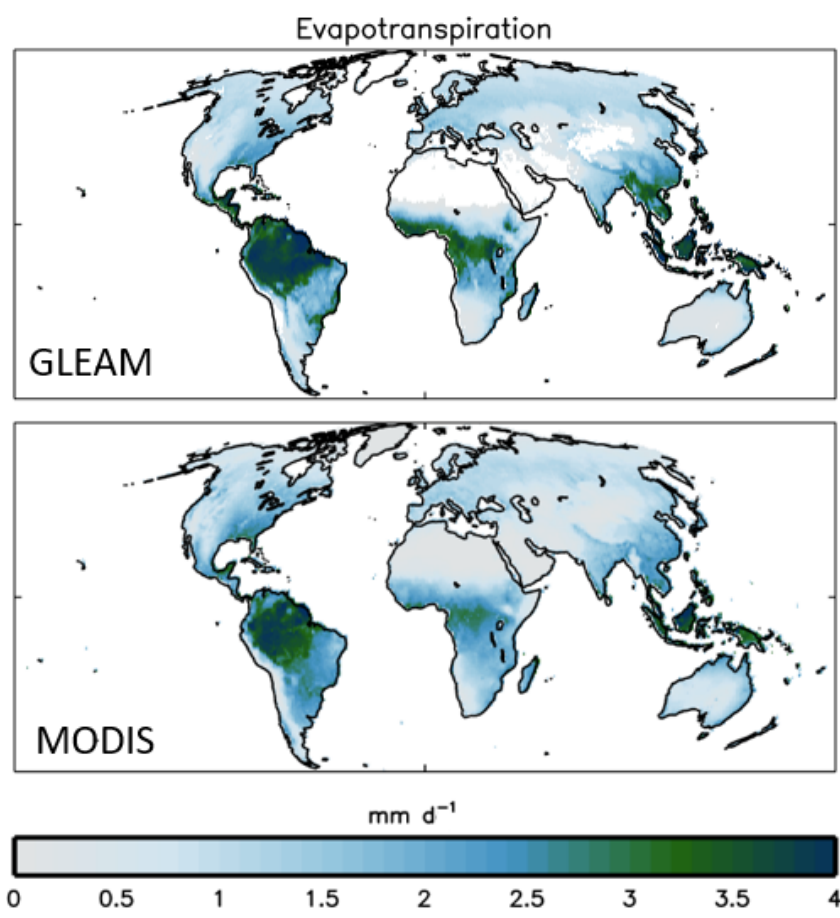

Figure 8. Surface evapotranspiration benchmarks derived from GLEAM (Miralles et al., 2011) and MODIS (Mu et al., 2013), as generated by ILAMB (Collier et al., 2018), covering 1980-2011 and 2000-2013, respectively.

The suite, as provided, includes a standardised suite control approach to manage both the necessary stages of initialising and running an experiment as well as scheduling resources and time slots on the supercomputer. This is shown graphically in Fig. 5. The suite is set up to run three separate instances of JULES. The first initialises and reconfigures an initial start condition. The second starts from the reconfigured start condition and spins up the states of snow, soil moisture and temperatures by cycling over 1860-1879 climate using fixed pre-industrial $\mathrm{CO}_{2}$. This is optional according to whether the initial state is already spun-up and is controlled by a switch ( $l \_$spinup). Setting this switch to false bypasses the spinup entirely. The number of cycles required and the period to loop over can also be set. Each new cycle of spinup is submitted as a new job taking the initial conditions from the end of the previous cycle. The final task is to perform the transient experiment taking either initial conditions from the reconfiguration step or the final spinup cycle. These settings are all available under Runtime Configuration and Runtime Configuration > Spinup Options. The transient run makes uses of varying climate and atmospheric $\mathrm{CO}_{2}$. As a standard, the transient experiment has a 10-year cycle interval to allow a complete cycle to complete within the time limits on the supercomputer. It is worth noting that JULES vn5.3 is unable to perform full bit-comparable restarts. This means the model prognostics at the end of one submission 

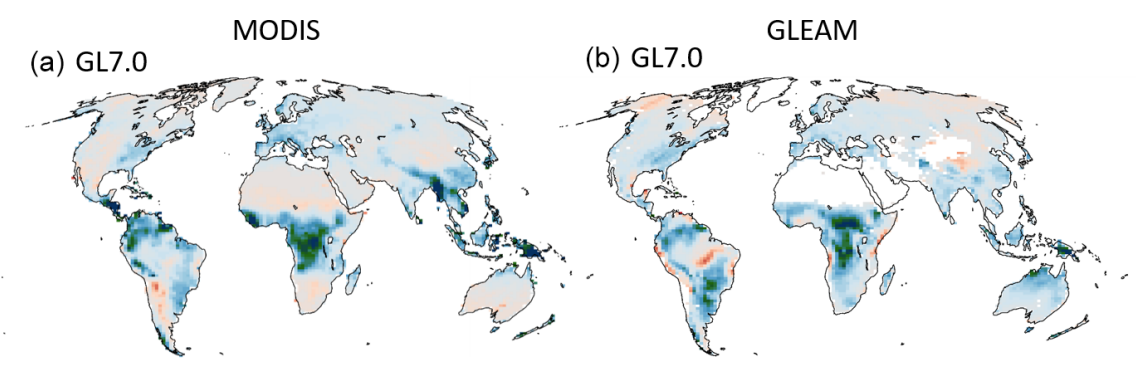

(c) GL7.2

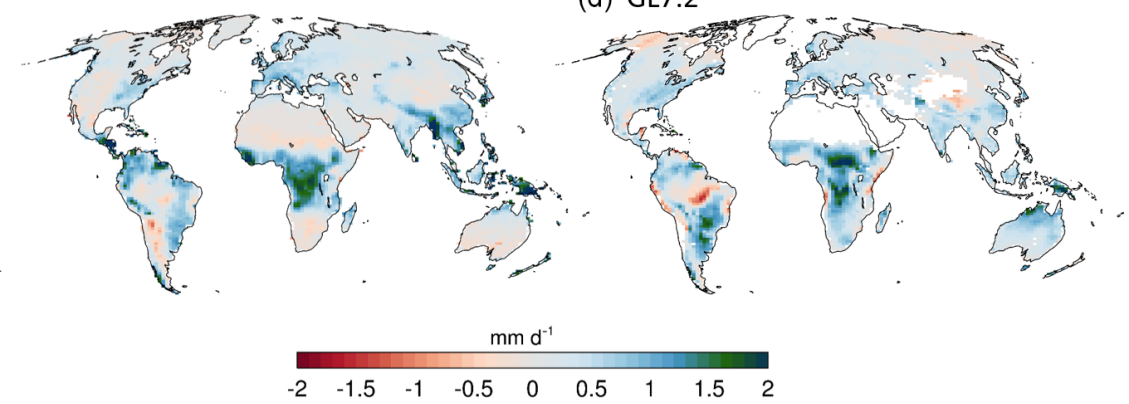

Figure 9. Evapotranspiration biases simulated by GL7.0 (a, b) and GL7.2 (c, d) for MODIS (a, c) and GLEAM (b, d) benchmarks. MODIS means are for 2000-2013 and GLEAM for 1980-2011. Biases are calculated as the difference between the model and observations.
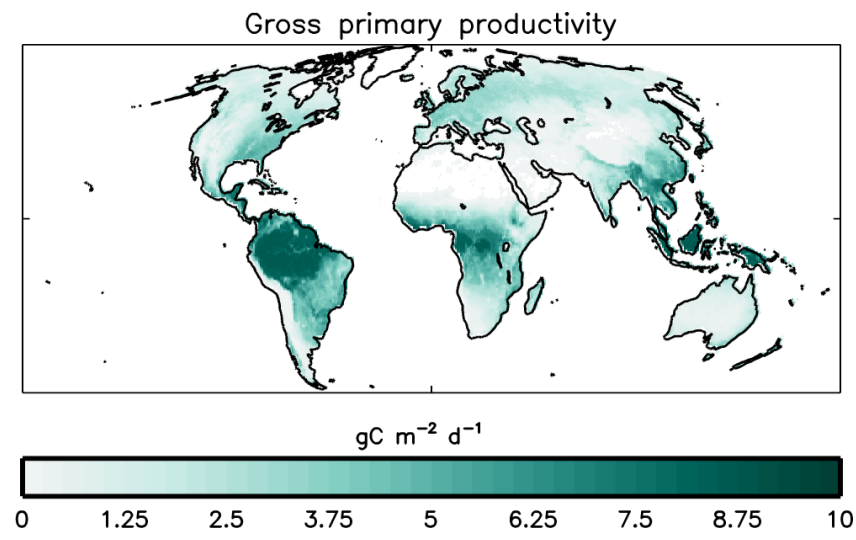

Figure 10. GPP (1982-2008) benchmark derived from FLUXNETMTE (Jung et al., 2010) as generated by ILAMB (Collier et al., 2018).

differ slightly from those used at the start of the next. The exact state at the end of the transient run will therefore be dependent on the number of spinup and transient cycles used.

\section{JULES-GL7 evaluation}

In this section, we evaluate the CRU-NCEPv7 historical experimental setup of the JULES-GL7 model configuration. We follow the approach of the International Land Model Benchmarking (ILAMB) project tool (Collier et al., 2018) to compare model simulations against observational data. However, due to technical limitations, we are unable to use the full benchmarking range that ILAMB includes. Here, we as- sess model performance against three key metrics covering surface energy balance, hydrology and vegetation productivity. The metrics are annual mean albedo, evapotranspiration and gross primary productivity, and they are benchmarked against observationally based datasets available in ILAMB. The aim here is not to perform a full analysis of model skill but to establish a few important benchmarks against which model developments can be compared and evaluated. In time, it is planned that the standardised JULES suite will be fully compatible with ILAMB, allowing for a full model evaluation and benchmarking to be completed in a straightforward and standardised way. Furthermore, caution should be taken in benchmarking a model using a single forcing dataset. As part of the Land Surface, Snow and Soil Moisture Model Intercomparison Project (LS3MIP; van den Hurk et al., 2016), this configuration will be setup with GSWP3 forcing data, which in time will be made available to the community. A second dataset will allow sampling of model uncertainty arising from forcing data variation.

Surface albedo is simulated in the model as described in Sect. 2.2. Globally, the observed land surface albedo is generally higher in snow-covered regions and deserts, as shown in the MODIS satellite data (Fig. 6). As noted in Sect. 2.2.1, the simulated albedo in JULES-GL7.0 and 7.2 are exactly the same, despite having different canopy radiation options, as the differences only affect light availability for photosynthesis. Overall, we find the model is too bright with a globally positive bias (Table 4). However, Fig. 7 shows that the bias is spatially variable, with the largest biases (both positive and negative) found in the high latitudes and other snow-covered regions. In general, in this experimental setup, we find the 
(a)

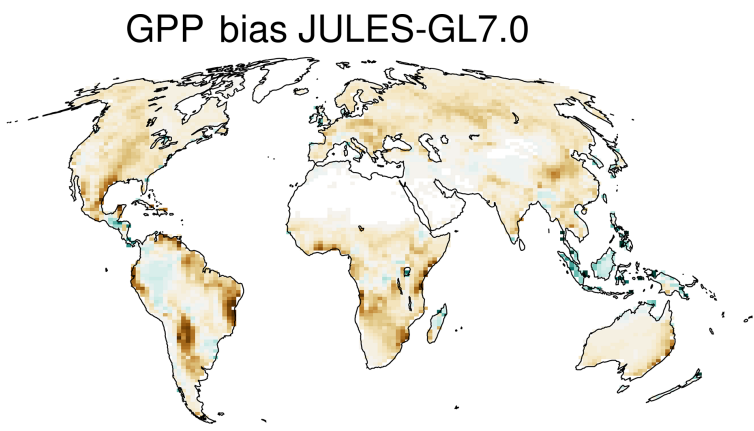

(b)

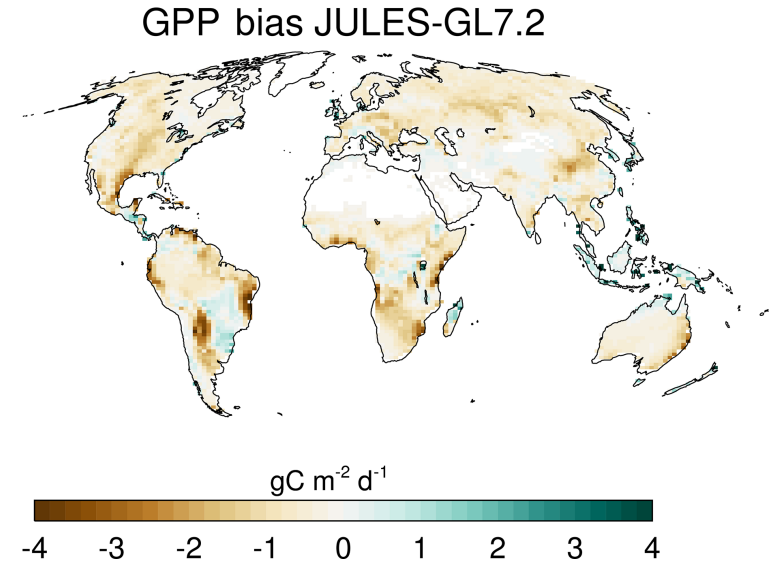

Figure 11. GPP biases simulated by GL7.0 (a) and GL7.2 (b) against the FLUXNET-MTE dataset. Means are for 1982-2008. Biases are calculated as the difference between the model and observations.

surface is too bright in regions of boreal forests and too dark across the far north in the tundra regions.

Evapotranspiration is benchmarked against two observational products: GLEAM (Miralles et al., 2011) and MODIS (Mu et al., 2013). There is uncertainty in the two datasets, with large differences in the magnitude of evapotranspiration particularly over the tropical regions (Fig. 8). Both GL7.0 and 7.2 have large positive biases over much of the world, and these are strongest over the tropics (up to $2 \mathrm{mmd}^{-1}$; Fig. 9). However, the exact location of the largest biases differs between MODIS and GLEAM. GLEAM suggests a dipole pattern over central Africa, while MODIS has a centralised positive bias, implying there is a degree of observational uncertainty that needs to be accounted for. Overall, the biases are slightly reduced in GL7.2 (Table 4).

Although GL7 is mainly intended for studying the exchange of momentum, heat and water, the configuration also underpins the carbon cycle configuration, and photosynthesis is strongly linked to evapotranspiration through the stomatal conductance model. It is therefore worth benchmarking the model's ability to simulate GPP. Here, we compare simulated GPP against the Fluxnet-MTE product (Fig. 10; Jung et al., 2010). Figure 11 shows that GL7.0 and 7.2 correctly predict that GPP is highest in tropical forests and low in arid areas, but there is a substantial negative bias in most biomes, with the exception of tropical forests. GL7.2 is an improvement over GL7.0, with a global total GPP of $95.4 \mathrm{GtC}$ compared with $91.1 \mathrm{GtC}$ in GL7.0. However, this is substantially lower than the $119 \mathrm{GtC}$ in the reference dataset.

\section{Summary}

JULES-GL7.0 is the stand-alone version of the land surface configuration underpinning the HadGEM3-GC3.1 climate model that is being run as part of the CMIP6 round of global climate modelling experiments. It is a comprehensive model simulating the exchange of heat, water and momentum developed as part of the coupled climate model and extracted here for use by the community.

It has been shown that both JULES-GL7.0 and JULESGL7.2 can capture the large-scale features of surface albedo, evapotranspiration and GPP; however, there are substantial biases that future updates to the configuration should attempt to reduce. There is also substantial uncertainty in observational evaluation datasets and the forcing for driving the model (Collier et al., 2018), which remains to be accounted for. Caution therefore needs to be taken to avoid overfitting the model to just a few datasets without a full appreciation of the uncertainties involved. In time, we plan to add additional forcing datasets to the standard configuration and the ability to benchmark against the full capability available in ILAMB.

This configuration and the ability to run the model are provided to the land surface modelling community to promote community engagement in the advancement of land surface science whether through application in their individual study, for use in model intercomparison studies such as LS3MIP (van den Hurk et al., 2016) or to promote community science developments progressing onto the main JULES trunk and into the major science configurations that underpin weather and climate forecasting in the UK. 


\section{Appendix A: Running JULES-GL7}

This section describes how to access and run the JULESGL7.0 and JULES-GL7.2 suites provided in JULES version 5.3. It is recommended that the latest version is used, which is available from https://code.metoffice.gov.uk/trac/jules/wiki/ JulesConfigurations (last access: 31 January 2020) (login required), in order to benefit from bug fixes, ease of testing and implementing developments, which can only take place at the head of the JULES code trunk.

\section{A1 Compute platform setup}

The JULES-GL7.0 and JULES-GL7.2 configurations are available as Rose suites at https://code.metoffice.gov.uk/ trac/roses-u/browser/b/b/3/1/6/trunk (last access: 31 January 2020) and https://code.metoffice.gov.uk/trac/roses-u/ browser/b/b/5/4/3/trunk (last access: 31 January 2020), respectively. Note that access will be required to the Met Office Science Repository Service (https://code.metoffice.gov. uk/trac/home, last access: 31 January 2020) and is available to those who have signed the JULES user agreement. JULES is freely available for non-commercial research use, as set out in the JULES user terms and conditions (http:// jules-lsm.github.io/access_req/JULES_Licence.pdf, last access: 31 January 2020). The easiest way to access the repository is by completing the online form here: http:// jules-lsm.github.io/access_req/JULES_access.html (last access: 31 January 2020).

The suite is configured to run on both the Met Office CRAY XC40 or the JASMIN (http://www.jasmin.ac. uk/, last access: 31 January 2020) platform provided by the Science and Technology Facilities Council UK. For non-Met Office collaborators, JASMIN is the most suitable platform for running JULES simulations. JASMIN access is available for all UK-based researchers who consider themselves part of the NERC (https://nerc.ukri.org/, last access: 31 January 2020) community. JASMIN is also available for non-UK based researchers who are interested in JULES. Once you have access to JASMIN, you will need to request access to the JULES group workspace (/group_workspaces/jasmin2/jules), which can be done here: https://accounts.jasmin.ac.uk/services/group workspaces/jules/ (last access: 31 January 2020). Met Office CRAY XC40 users will need access to the xcel00 and/or xcef00 machines.

Installing the suite requires access to the Met Office suite and code management tools available on both JASMIN and the Met Office Linux estate. To access the tools, please follow the guidelines in Sect. A5 of the Appendix. Once you have access to the necessary compute platforms, repository and tools, you are ready to start your run.

The suite is designed for ease of use, to enable the maximum number of users to access it. The suite is configured to extract the code from the repository, build on the appropriate platform, sourcing appropriate libraries and then run using the appropriate forcing and ancillaries. Most users should be able to set a standard run going in just a few steps.

\section{A2 Setting up the model configuration}

The standard JULES-GL7.0 (JULES-GL7.2) suite, u-bb316, $(u-b b 543)$ has been configured to minimise the steps necessary to be able to run the standard configuration; however, a few important steps and checks remain. It is assumed that a JASMIN user has logged into the jasmin-cylc node and a Met Office user is accessing CRAY via a Linux desktop.

1. Create a new suite:

rosie copy u-bb316

This will create a new suite of your own in which changes can be made and tracked using the Met Office Science Repository Service. Remember to commit any changes back to the repository with $\mathrm{fcm}$ commit. Rosie copy $u$-bb316 results in a new suite with a similar id in alphanumeric order, e.g. $u$-ab123. You should replace $u$-ab123 with your suite id in the following commands.

2. The rosie copy command will create a local copy of the new suite in the $\sim /$ roses directory. You can change directory to this suite.

Once the suite is installed, you can use the Rose GUI editor to check the suite setup. There are a number of platform-specific aspects to be checked. To open the GUI, the following is necessary:

rose edit $-\mathrm{C} \sim /$ roses/u-ab123/

a. Build options > JULES_FCM - this variable points to the location of the code to be compiled. In the standard case, this should point to the trunk; however, this could equally point to a branch to test a new development. An important point to note is that the CRAY uses an internal "mirror" copy of the repository held in the cloud. This avoids downtime when the repository is unavailable. This is indicated by an " $m$ " in the repository shortcuts. This should be fcm:jules.xm and fcm:jules.x on CRAY and JASMIN, respectively. This is handled in the background by the Cylc control system; however, failure to set this correctly will result in a build failure.

b. Platform-specific $>$ build and run mode - this radar button is used to set up the platform-specific build and installation. This should be Met Office-cray$x c 40$ and Jasmin-Lotus on the CRAY and JASMIN platforms, respectively. 
c. Runtime configuration > MPI_NUM_TASKS - up to 16 MPI tasks are available on JASMIN. More are available on the CRAY for faster runtime. Overall, 16 MPI tasks is a recommended setup. However, 18 MPI tasks (with two OpenMPs; OMPs) make a fuller use of a single Broadwell node on the CRAY.

d. Runtime configuration > OMP_NUM_TASKS more recently releases of JULES support more OpenMP threads. A suitable number of tasks is two.

The suite is now installed and ready to run. On the CRAY platform, the submission can be made from the local machine. On JASMIN, it is recommended to use the Cylc workflow machine jasmin-cylc. The suite can be submitted to the scheduler.

rose suite-run-c $\sim /$ roses/u-ab123/

3. Assuming the suite submits correctly, the next step is to monitor progress. Met Office and JASMIN users will automatically see the suite control GUI. However, the suite can be monitored by one of the two following options:

cylc scan $-\mathrm{C}$ will show the state of running suites.

tail -f /cylc-run/u-ab123/log/suite/ log will print to screen the current status of $\mathrm{u}-\mathrm{ab} 123$.

4. The output from the suite is automatically written to a directory:

a. \$DATADIR/jules_output/u-ab123 on CRAY;

b. /work/scratch/\$USER/u-ab123 on JASMIN.

Note that the scratch workspace on JASMIN is not for permanent storage of model output.

\section{A3 Making changes to model configuration}

The purpose of making a standard science configuration and experimental setup available is not so users can reproduce the same results but to encourage further development and testing, whether that involves new and novel diagnostics and evaluation or new processes and ancillary information. This should be done relative to the "benchmark" standard configuration and experimental setup. To modify the configurations, users should copy the standard suite as above and switch the code base to point to the user's branch and revision number. Any new parameters and switches can then be added to the app configuration file - this can be done through the GUI or by editing the configuration file directly ( $/$ roses/u-ab123/app/rose-suite.conf).

Note that the model code needs to be consistent with the setup in the app. Any modifications to the suite should be committed and documented on a JULES ticket similar to the one documenting the JULES-GL7 release (https://code.metoffice.gov.uk/trac/jules/ticket/837,

last access: 31 January 2020).

Model developers should use the suite and information presented here in combination with the JULES technical documentation found in Best et al. (2011) and Clark et al. (2011).

\section{A4 Inter-version compatibility}

The JULES-GL7 model configurations are independent of the code release, as it is a requirement of any modification to the JULES code base that the major configurations are scientifically reproducible between code versions. This is not exactly the same as them being reproducible to the bit level, as some changes are permitted; for instance, changing the order of a do loop can have benefits for runtime but lead to changes at the bit level. From a user perspective, the differences between model releases should be pragmatically indistinguishable. It is intended that the JULES-GL7 configurations will be made available at each model release, and the latest release is preferable if undertaking configuration development. Users of the configuration may find benefits in the latest version through technical improvements to suite control tools including user interfaces and code optimisation reducing runtime. It is therefore preferable to use the latest available configuration. At some point, when a configuration is deemed superseded, the guarantee of backwards compatibility will be dropped and code modules may be removed from the code base and no longer supported.

\section{A5 Setting up the JASMIN work environment}

The following assumes you have access to JASMIN as outlined in Sect. 5. This section outlines the necessary steps to set up the necessary work environment.

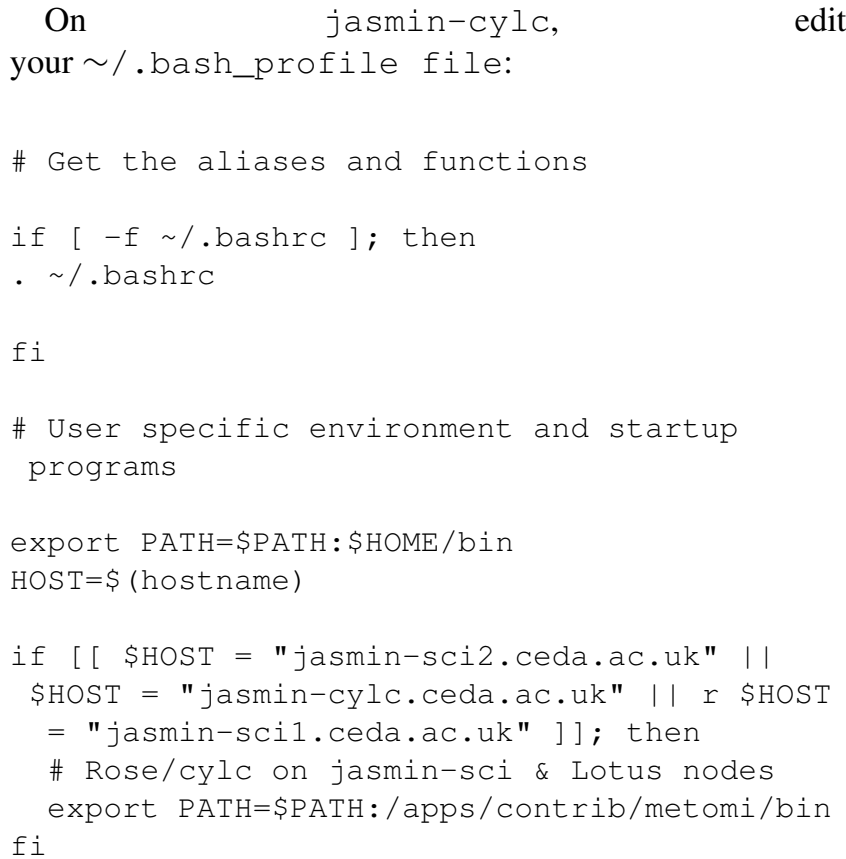


On jasmin-cylc, edit your $\sim /$.bashrc file at the top:

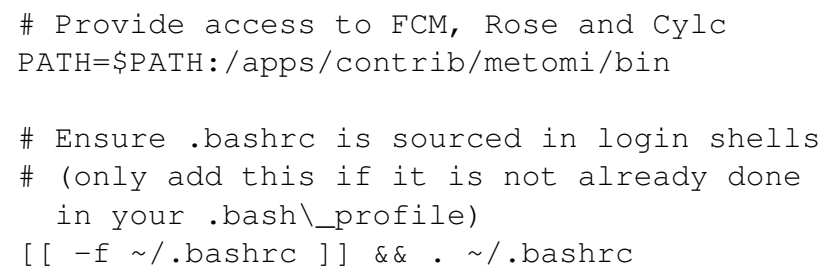

At the bottom,

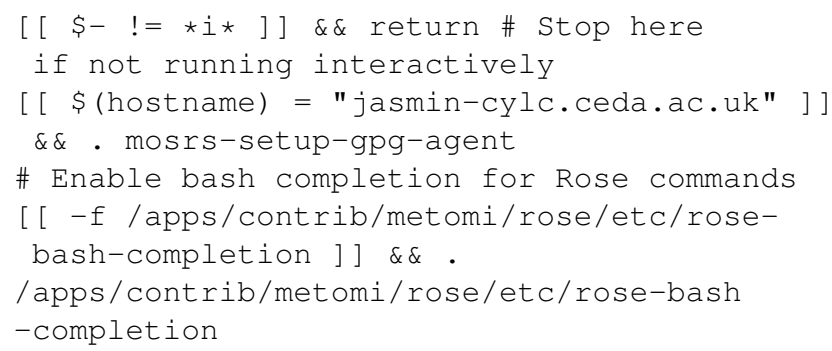

Now, whenever logging in to jasmin-cylc, you should be prompted for your Met Office Science Repository Service password.

A further setup for JASMIN and MOSRS requires an update to your $\sim /$. subversion/servers file. Please add the following and do not forget to give the corresponding username (change myusername to your MOSRSusername).

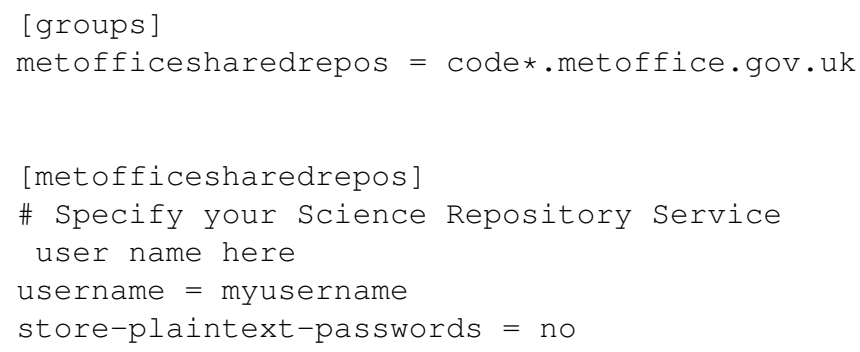

In the $\sim /$. subversion/config file, comment any lines starting with

\#password-stores $=$

Create the following configuration file $\sim /$.metomi/fcm/keyword.cfg and add the following lines:

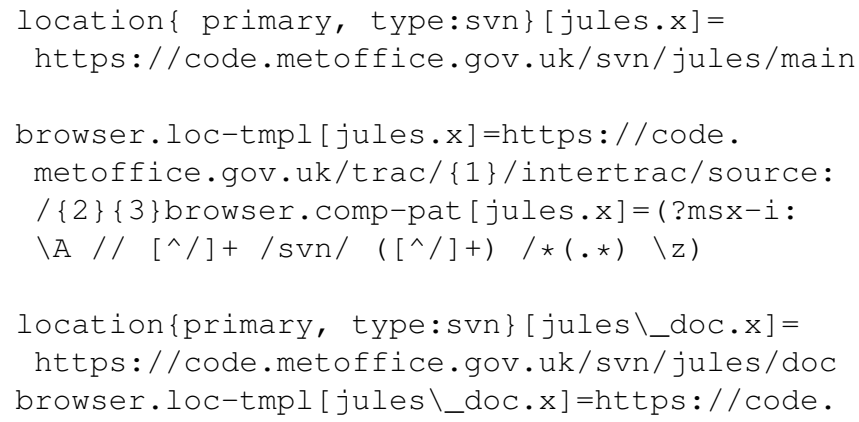

metoffice.gov.uk/trac/\{1\}/intertrac/source: $/\{2\}\{3\}$ browser.comp-pat [jules $\backslash$ doc.x $]=$ $(? \mathrm{msx}-\mathrm{i}: \backslash \mathrm{A} / /[\wedge /]+/ \operatorname{svn} /([\wedge /]+) / \star(. *) \backslash z)$

Add the following lines on the $\sim /$.metomi/rose.conf file if missing (change myusername to your MOSRS-username):

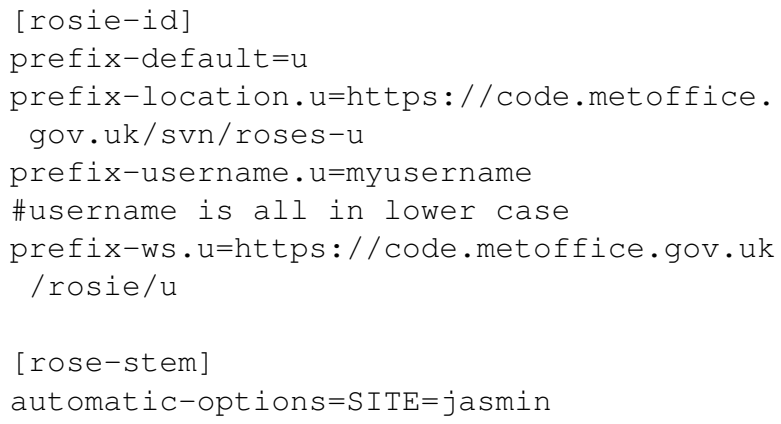

This can be checked by running

rose config 
Appendix B: Plant functional type, leaf area index and canopy height cross-walking tables

Table B1. PFT fraction lookup table for vegetated PFTs only. BLT indicates broadleaf tree; NLT indicates needleleaf tree. These lookup tables are used in conjunction with Eqs. (1) and (2).

\begin{tabular}{|c|c|c|c|c|c|c|c|c|c|}
\hline & BLT & NLT & $\mathrm{C}_{3}$ grass & $\mathrm{C}_{4}$ grass & Shrub & Urban & Water & Bare soil & Ice \\
\hline Evergreen needleleaf forest & 0 & 70 & 20 & 0 & 0 & 0 & 0 & 10 & 0 \\
\hline Evergreen broadleaf forest & 85 & 0 & 0 & 10 & 0 & 0 & 0 & 5 & 0 \\
\hline Deciduous needleleaf forest & 0 & 65 & 25 & 0 & 0 & 0 & 0 & 10 & 0 \\
\hline Deciduous broadleaf forest & 60 & 0 & 5 & 10 & 5 & 0 & 0 & 20 & 0 \\
\hline Mixed forest & 35 & 35 & 20 & 0 & 0 & 0 & 0 & 10 & 0 \\
\hline Closed shrub & 0 & 0 & 25 & 0 & 60 & 0 & 0 & 15 & 0 \\
\hline Open shrub & 0 & 0 & 5 & 10 & 35 & 0 & 0 & 50 & 0 \\
\hline Woody savannah & 50 & 0 & 15 & 0 & 25 & 0 & 0 & 10 & 0 \\
\hline Savannah & 20 & 0 & 0 & 75 & 0 & 0 & 0 & 5 & 0 \\
\hline Grassland & 0 & 0 & 70 & 15 & 5 & 0 & 0 & 10 & 0 \\
\hline Permanent wetland & 0 & 0 & 80 & 0 & 0 & 0 & 20 & 0 & 0 \\
\hline Cropland & 0 & 0 & 75 & 5 & 0 & 0 & 0 & 20 & 0 \\
\hline Urban & 0 & 0 & 0 & 0 & 0 & 100 & 0 & 0 & 0 \\
\hline Crop/natural mosaic & 5 & 5 & 55 & 15 & 10 & 0 & 0 & 10 & 0 \\
\hline Snow and ice & 0 & 0 & 0 & 0 & 0 & 0 & 0 & 0 & 100 \\
\hline Barren & 0 & 0 & 0 & 0 & 0 & 0 & 0 & 100 & 0 \\
\hline Water bodies & 0 & 0 & 0 & 0 & 0 & 0 & 100 & 0 & 0 \\
\hline
\end{tabular}

Table B2. Leaf area index lookup table for combinations of IGBP land cover class and plant functional type. These lookup tables are used in conjunction with Eqs. (1) and (2).

\begin{tabular}{|c|c|c|c|c|c|}
\hline & Broadleaf tree & Needleleaf tree & $\mathrm{C}_{3}$ grass & $\mathrm{C}_{4}$ grass & Shrub \\
\hline Evergreen needleleaf forest & & 6 & 2 & & \\
\hline Evergreen broadleaf forest & 9 & & 2 & 4 & \\
\hline Deciduous needleleaf forest & & 4 & 2 & & \\
\hline Deciduous broadleaf forest & 5 & & 2 & 4 & 3 \\
\hline Mixed forest & 5 & 6 & 2 & & \\
\hline Closed shrub & & & 2 & & 3 \\
\hline Open shrub & 5 & & 2 & 4 & 2 \\
\hline Woody savannah & 9 & & 4 & & 2 \\
\hline Savannah & 9 & & & 4 & \\
\hline Grassland & & & 3 & 4 & 3 \\
\hline Permanent wetland & 9 & & 3 & & 3 \\
\hline Cropland & 5 & & 5 & 4 & 3 \\
\hline Urban & & & & & \\
\hline Crop/natural mosaic & 5 & 6 & 4 & 4 & 3 \\
\hline Snow and ice & & & & & \\
\hline Barren & & & & & \\
\hline Water bodies & & & & & \\
\hline
\end{tabular}

Table B3. PFT-dependent canopy height scaling factor.

\begin{tabular}{rrrrrr}
\hline & Broadleaf tree & Needleleaf tree & $\mathrm{C}_{3}$ grass & $\mathrm{C}_{4}$ grass & Shrub \\
\hline Canopy height factor & 6.5 & 6.5 & 0.5 & 0.5 & 1.0 \\
\hline
\end{tabular}


Code availability. This work is based on JULES version 5.3 with specific configurations included in the form of suites. For full information regarding accessing the code and configurations, please refer to Appendix A.

Data availability. The model configuration and associated forcing data are available via the indicated methods in the manuscript (see Appendix A). JULES and associated configurations are freely available for non-commercial research use as set out in the JULES user terms and conditions (http://jules-lsm.github.io/access_req/ JULES_Licence.pdf, last access: 31 January 2020).

Author contributions. AW coordinated the preparation of the JULES version of the coupled GL7 suite and manuscript. JE led the initial development and testing of the GL7 configuration. AW, CDR and KSD undertook the technical development to make the configuration available via JASMIN and the standardised suite control. AW, CDR, JE, NG, ABH, AH, MH and ER all prepared sections of the manuscript. All authors contributed to the preparation of the manuscript.

Competing interests. The authors declare that they have no conflict of interest.

Acknowledgements. We thank Nicolas Viovy for providing the forcing data.

Financial support. This research has been supported by the BEIS and DEFRA Met Office Hadley Centre Climate Programme (MOHCCP) for 2018-2021 (MOHCCP grant). Andrew J. Wiltshire and Maria Carolina Duran Rojas acknowledge the support of the EU Horizon 2020 CRECENDO project (grant agreement no. 641816).

Review statement. This paper was edited by Tim Butler and reviewed by two anonymous referees.

\section{References}

Beljaars, A. C. M. and Holtslag, A. A. M.: Flux parameterization over land surfaces for atmospheric models, J. Appl. Meteorol., 30, 327-341, https://doi.org/10.1175/15200450(1991)030<0327:FPOLSF>2.0.CO;2, 1991.

Best, M. J.: Representing urban areas within operational numerical weather prediction models, Bound.-Lay. Meteorol., 114, 91-109, https://doi.org/10.1007/s10546-004-4834-5, 2005.

Best, M. J., Grimmond, C. S. B., and Villani, M. G.: Evaluation of the Urban Tile in MOSES using Surface Energy Balance Observations, Bound.-Lay. Meteorol., 118, 503-525, https://doi.org/10.1007/s10546-005-9025-5, 2006.

Best, M. J., Pryor, M., Clark, D. B., Rooney, G. G., Essery, R. L. H., Ménard, C. B., Edwards, J. M., Hendry, M. A., Porson, A.,
Gedney, N., Mercado, L. M., Sitch, S., Blyth, E., Boucher, O., Cox, P. M., Grimmond, C. S. B., and Harding, R. J.: The Joint UK Land Environment Simulator (JULES), model description Part 1: Energy and water fluxes, Geosci. Model Dev., 4, 677-699, https://doi.org/10.5194/gmd-4-677-2011, 2011.

Betts, R. A., Boucher, O., Collins, M., Cox, P. M., Falloon, P. D., Gedney, N., Hemming, D. L., Huntingford, C., Jones, C. D., Sexton, D. M. H., and Webb, M. J.: Projected increase in continental runoff due to plant responses to increasing carbon dioxide, Nature, 448, 1037-1041, https://doi.org/10.1038/nature06045, 2007.

Betts, R. A., Alfieri, L., Bradshaw, C., Caesar, J., Feyen, L., Friedlingstein, P., Gohar, L., Koutroulis, A., Lewis, K., Morfopoulos, C., Papadimitriou, L., Richardson, K. J., Tsanis, I., and Wyser, K.: Changes in climate extremes, fresh water availability and vulnerability to food insecurity projected at $1.5^{\circ} \mathrm{C}$ and $2{ }^{\circ} \mathrm{C}$ global warming with a higher-resolution global climate model, Philos. T. R. Soc. A, 376, 20160452, https://doi.org/10.1098/RSTA.2016.0452, 2018.

Calonne, N., Flin, F., Morin, S., Lesaffre, B., Rolland du Roscoat, S., and Geindreau, C.: Numerical and experimental investigations of the effective thermal conductivity of snow, Geophys. Res. Lett., 38, L23501, https://doi.org/10.1029/2011GL049234, 2011.

Clark, D. B., Mercado, L. M., Sitch, S., Jones, C. D., Gedney, N., Best, M. J., Pryor, M., Rooney, G. G., Essery, R. L. H., Blyth, E., Boucher, O., Harding, R. J., Huntingford, C., and Cox, P. M.: The Joint UK Land Environment Simulator (JULES), model description - Part 2: Carbon fluxes and vegetation dynamics, Geosci. Model Dev., 4, 701-722, https://doi.org/10.5194/gmd-4701-2011, 2011.

Collatz, G., Ribas-Carbo, M. and Berry, J.: Coupled PhotosynthesisStomatal Conductance Model for Leaves of $\mathrm{C}_{4}$ Plants, Funct. Plant Biol., 19, 519, https://doi.org/10.1071/PP9920519, 1992.

Collatz, G. J., Ball, J. T., Grivet, C., and Berry, J. A.: Physiological and environmental regulation of stomatal conductance, photosynthesis and transpiration: a model that includes a laminar boundary layer, Agr. Forest Meteorol., 54, 107-136, https://doi.org/10.1016/0168-1923(91)90002-8, 1991.

Collier, N., Hoffman, F. M., Lawrence, D. M., Keppel-Aleks, G., Koven, C. D., Riley, W. J., Mu, M., and Randerson, J. T.: The International Land Model Benchmarking (ILAMB) System: Design, Theory, and Implementation, J. Adv. Model. Earth Syst., 10, 2731-2754, https://doi.org/10.1029/2018MS001354, 2018.

Collins, W. J., Bellouin, N., Doutriaux-Boucher, M., Gedney, N., Halloran, P., Hinton, T., Hughes, J., Jones, C. D., Joshi, M., Liddicoat, S., Martin, G., O’Connor, F., Rae, J., Senior, C., Sitch, S., Totterdell, I., Wiltshire, A., and Woodward, S.: Development and evaluation of an Earth-System model - HadGEM2, Geosci. Model Dev., 4, 1051-1075, https://doi.org/10.5194/gmd-4-10512011, 2011.

Cox, P., Huntingford, C., and Harding, R.: A canopy conductance and photosynthesis model for use in a GCM land surface scheme, J. Hydrol., 212-213, 79-94, https://doi.org/10.1016/S00221694(98)00203-0, 1998.

Cox, P. M., Betts, R. A., Bunton, C. B., Essery, R. L. H., Rowntree, P. R., and Smith, J.: The impact of new land surface physics on the GCM simulation of climate and climate sensitivity, Clim. Dynam., 15, 183-203, 1999. 
De Kauwe, M. G., Disney, M. I., Quaife, T., Lewis, P., and Williams, M.: An assessment of the MODIS collection 5 leaf area index product for a region of mixed coniferous forest, Remote Sens. Environ., 115, 767-780, https://doi.org/10.1016/J.RSE.2010.11.004, 2011.

Dharssi, I., Vidale, P. L., Verhoef, A., Macpherson, B., Jones, C. and Best, M.: New soil physical properties implemented in the Unified Model at PS18, Meteorology Research and Development Technical Report 528, Met. Office, Exeter, UK, available at: https://digital.nmla.metoffice.gov.uk/ IO_01baed78-35d1-426d-aad0-88357bb493b2/ (last access: 16 September 2019), 2009.

Dlugokencky, E. and Tans, P.: Trends in atmospheric carbon dioxide, National Oceanic \& Atmospheric Administration, Earth System Research Laboratory (NOAA/ESRL), available at: http: //www.esrl.noaa.gov/gmd/ccgg/trends, last access: 7 October 2015

Dutra, E., Balsamo, G., Viterbo, P., Miranda, P. M., Beljaars, A., Schär, C., and Elder, K.: An Improved Snow Scheme for the ECMWF Land Surface Model: Description and Offline Validation, J. Hydrometeorol., 11, 899-916, https://doi.org/10.1175/2010JHM1249.1, 2010.

Edwards, J. M. and Slingo, A.: Studies with a Flexible New Radiation Code. I: Choosing a Configuration for a Large-scale Model, Q. J. Roy. Meteor. Soc., 122, 689-719, https://doi.org/10.1002/qj.49712253107, 1996.

Essery, R. L. H., Best, M. J., Betts, R. A., Cox, P. M., Taylor, C. M., Essery, R. L. H., Best, M. J., Betts, R. A., Cox, P. M., and Taylor, C. M.: Explicit Representation of Subgrid Heterogeneity in a GCM Land Surface Scheme, J. Hydrometeorol., 4, 530-543, https://doi.org/10.1175/15257541(2003)004<0530:EROSHI>2.0.CO;2, 2003.

Eyring, V., Bony, S., Meehl, G. A., Senior, C. A., Stevens, B., Stouffer, R. J., and Taylor, K. E.: Overview of the Coupled Model Intercomparison Project Phase 6 (CMIP6) experimental design and organization, Geosci. Model Dev., 9, 1937-1958, https://doi.org/10.5194/gmd-9-1937-2016, 2016.

Field, C. B., Jackson, R. B., and Mooney, H. A.: Stomatal responses to increased $\mathrm{CO}_{2}$ : implications from the plant to the global scale, Plant Cell Environ., 18, 1214-1225, https://doi.org/10.1111/j.1365-3040.1995.tb00630.x, 1995.

Gedney, N. and Cox, P. M.: The Sensitivity of Global Climate Model Simulations to the Representation of Soil Moisture Heterogeneity, J. Hydrometeorol., 4, 1265-1275, https://doi.org/10.1175/15257541(2003)004<1265:TSOGCM>2.0.CO;2, 2003.

Harper, A. B., Cox, P. M., Friedlingstein, P., Wiltshire, A. J., Jones, C. D., Sitch, S., Mercado, L. M., Groenendijk, M., Robertson, E., Kattge, J., Bönisch, G., Atkin, O. K., Bahn, M., Cornelissen, J., Niinemets, Ü., Onipchenko, V., Peñuelas, J., Poorter, L., Reich, P. B., Soudzilovskaia, N. A., and Bodegom, P. V.: Improved representation of plant functional types and physiology in the Joint UK Land Environment Simulator (JULES v4.2) using plant trait information, Geosci. Model Dev., 9, 2415-2440, https://doi.org/10.5194/gmd-9-2415-2016, 2016.

Harris, I., Jones, P. D., Osborn, T. J., and Lister, D. H.: Updated high-resolution grids of monthly climatic observations - the CRU TS3.10 Dataset, Int. J. Climatol., 34, 623-642, https://doi.org/10.1002/joc.3711, 2014.
Jogireddy, V., Cox, P. M., Huntingford, C., Harding, R. J., and Mercado, L. M.: An improved description of canopy light interception for use in a GCM land-surface scheme: calibration and testing against carbon fluxes at a coniferous forest, available at: https://library.metoffice.gov.uk/Portal/ Default/en-GB/RecordView/Index/252258 (last access: 31 January 2020), 2006.

Jones, C. P.: Ancillary file generation for the UM, Unified Model Documentation Paper \#73, Met Office Technical Documentation, 1998.

Jung, M., Reichstein, M., Ciais, P., Seneviratne, S. I., Sheffield, J., Goulden, M. L., Bonan, G., Cescatti, A., Chen, J., de Jeu, R., Dolman, A. J., Eugster, W., Gerten, D., Gianelle, D., Gobron, N., Heinke, J., Kimball, J., Law, B. E., Montagnani, L., Mu, Q., Mueller, B., Oleson, K., Papale, D. Richardson, A. D., Roupsard, O., Running, S., Tomelleri, E., Viovy, N., Weber, U., Williams, C., Wood, E., Zaehle, S., and Zhang, K.: Recent decline in the global land evapotranspiration trend due to limited moisture supply, Nature, 467, 951-954, https://doi.org/10.1038/nature09396, 2010.

Lehner, B., Verdin, K., and Jarvis, A.: HydroSHEDS technical documentation, version 1.0, HydroSHEDS Tech. Doc. (Version 1.0). World Wide Fund Nature, Washington, DC, available at: https://hydrosheds.cr.usgs.gov/ webappcontent/HydroSHEDS_TechDoc_v10.pdf and https: //hydrosheds.cr.usgs.gov/HydroSHEDS_doc_v1_draft_dec7.doc (last access: 4 December 2018), 2006.

Le Quéré, C., Moriarty, R., Andrew, R. M., Canadell, J. G., Sitch, S., Korsbakken, J. I., Friedlingstein, P., Peters, G. P., Andres, R. J., Boden, T. A., Houghton, R. A., House, J. I., Keeling, R. F., Tans, P., Arneth, A., Bakker, D. C. E., Barbero, L., Bopp, L., Chang, J., Chevallier, F., Chini, L. P., Ciais, P., Fader, M., Feely, R. A., Gkritzalis, T., Harris, I., Hauck, J., Ilyina, T., Jain, A. K., Kato, E., Kitidis, V., Klein Goldewijk, K., Koven, C., Landschützer, P., Lauvset, S. K., Lefèvre, N., Lenton, A., Lima, I. D., Metzl, N., Millero, F., Munro, D. R., Murata, A., Nabel, J. E. M. S., Nakaoka, S., Nojiri, Y., O’Brien, K., Olsen, A., Ono, T., Pérez, F. F., Pfeil, B., Pierrot, D., Poulter, B., Rehder, G., Rödenbeck, C., Saito, S., Schuster, U., Schwinger, J., Séférian, R., Steinhoff, T., Stocker, B. D., Sutton, A. J., Takahashi, T., Tilbrook, B., van der Laan-Luijkx, I. T., van der Werf, G. R., van Heuven, S., Vandemark, D., Viovy, N., Wiltshire, A., Zaehle, S., and Zeng, N.: Global Carbon Budget 2015, Earth Syst. Sci. Data, 7, 349-396, https://doi.org/10.5194/essd-7-349-2015, 2015.

Le Quéré, C., Andrew, R. M., Friedlingstein, P., Sitch, S., Pongratz, J., Manning, A. C., Korsbakken, J. I., Peters, G. P., Canadell, J. G., Jackson, R. B., Boden, T. A., Tans, P. P., Andrews, O. D., Arora, V. K., Bakker, D. C. E., Barbero, L., Becker, M., Betts, R. A., Bopp, L., Chevallier, F., Chini, L. P., Ciais, P., Cosca, C. E., Cross, J., Currie, K., Gasser, T., Harris, I., Hauck, J., Haverd, V., Houghton, R. A., Hunt, C. W., Hurtt, G., Ilyina, T., Jain, A. K., Kato, E., Kautz, M., Keeling, R. F., Klein Goldewijk, K., Körtzinger, A., Landschützer, P., Lefèvre, N., Lenton, A., Lienert, S., Lima, I., Lombardozzi, D., Metzl, N., Millero, F., Monteiro, P. M. S., Munro, D. R., Nabel, J. E. M. S., Nakaoka, S., Nojiri, Y., Padin, X. A., Peregon, A., Pfeil, B., Pierrot, D., Poulter, B., Rehder, G., Reimer, J., Rödenbeck, C., Schwinger, J., Séférian, R., Skjelvan, I., Stocker, B. D., Tian, H., Tilbrook, B., Tubiello, F. N., van der Laan-Luijkx, I. T., van der 
Werf, G. R., van Heuven, S., Viovy, N., Vuichard, N., Walker, A. P., Watson, A. J., Wiltshire, A. J., Zaehle, S., and Zhu, D.: Global Carbon Budget 2017, Earth Syst. Sci. Data, 10, 405-448, https://doi.org/10.5194/essd-10-405-2018, 2018.

Loveland, T. R. and Belward, A. S.: The IGBP-DIS global $1 \mathrm{~km}$ land cover data set, DISCover: First results, Int. J. Remote Sens., 18, 3289-3295, https://doi.org/10.1080/014311697217099, 1997.

Loveland, T. R., Reed, B. C., Brown, J. F., Ohlen, D. O., Zhu, Z., Yang, L. W. M. J., and Merchant, J. W.: Development of a global land cover characteristics database and IGBP DISCover from 1 km AVHRR data, Int. J. Remote Sens., 21, 1303-1330, 2000.

MacKay, M. D. and Bartlett, P. A.: Estimating canopy snow unloading timescales from daily observations of albedo and precipitation, Geophys. Res. Lett., 33, L19405, https://doi.org/10.29/2006GL027521, 2006.

Manners, J., Edwards, J. M., Hill, P., and Thelen, J.-C.: SOCRATES (Suite Of Community RAdiative Transfer codes based on Edwards and Slingo), Met Office, UK, available at: https://code. metoffice.gov.uk/trac/socrates, (last access: 30 January 2020), 2018.

Marthews, T. R., Dadson, S. J., Lehner, B., Abele, S., and Gedney, N.: High-resolution global topographic index values for use in large-scale hydrological modelling, Hydrol. Earth Syst. Sci., 19, 91-104, https://doi.org/10.5194/hess-19-91-2015, 2015.

Mercado, L. M., Huntingford, C., Gash, J. H. C., Cox, P. M., and Jogireddy, V.: Improving the representation of radiation interception and photosynthesis for climate model applications, Tellus B, 59, 553-565, https://doi.org/10.1111/j.1600-0889.2007.00256.x, 2007.

Miralles, D., Holmes, T., De Jeu, R., and Gash, J.: Global land-surface evaporation estimated from satellite-based observations, available at: http://dare.ubvu.vu.nl/bitstream/handle/1871/ 39825/277927.pdf?sequence=1 (last access: 11 April 2019), 2011.

Mu, Q., Zhao, M., and Running, S.: MODIS global terrestrial evapotranspiration (ET) product (NASA MOD16A2/A3) collection 5. NASA Headquarters, available at: https://scholarworks.umt.edu/ ntsg_pubs/268/ (last access: 11 April 2019), 2013.

Osborne, T., Gornall, J., Hooker, J., Williams, K., Wiltshire, A., Betts, R., and Wheeler, T.: JULES-crop: a parametrisation of crops in the Joint UK Land Environment Simulator, Geosci. Model Dev., 8, 1139-1155, https://doi.org/10.5194/gmd-8-11392015, 2015.

Rooney, G. G. and Jones, I. D.: Coupling the 1-D lake model FLake to the community land-surface model JULES, Boreal Environ. Res., 15, 501-512, 2010.

Sellers, P. J.: Canopy reflectance, photosynthesis and transpiration, Int. J. Remote Sens., 6, 1335-1372, https://doi.org/10.1080/01431168508948283, 1985.

Sellers, P. J., Bounoua, L., Collatz, G. J., Randall, D. A., Dazlich, D. A., Los, S. O., Berry, J. A., Fung, I., Tucker, C. J., Field, C. B., and Jensen, T. G.: Comparison of Radiative and Physiological Effects of Doubled Atmospheric $\mathrm{CO}_{2}$ on Climate, Science, 271, 1402-1406, https://doi.org/10.1126/science.271.5254.1402, 1996.

Shannon, S., Smith, R., Wiltshire, A., Payne, T., Huss, M., Betts, R., Caesar, J., Koutroulis, A., Jones, D., and Harrison, S.: Global glacier volume projections under high-end climate change sce- narios, The Cryosphere, 13, 325-350, https://doi.org/10.5194/tc13-325-2019, 2019.

Snyder, W. C., Wan, Z., Zhang, Y., and Feng, Y.-Z.: Classificationbased emissivity for land surface temperature measurement from space, Int. J. Remote Sens., 19, 2753-2774, https://doi.org/10.1080/014311698214497, 1998.

Taillandier, A.-S., Domine, F., Simpson, W. R., Sturm, M., and Douglas, T. A.: Rate of decrease of the specific surface area of dry snow: Isothermal and temperature gradient conditions, J. Geophys. Res., 112, F03003, https://doi.org/10.1029/2006JF000514, 2007.

The HadGEM2 Development Team: Martin, G. M., Bellouin, N., Collins, W. J., Culverwell, I. D., Halloran, P. R., Hardiman, S. C., Hinton, T. J., Jones, C. D., McDonald, R. E., McLaren, A. J., O'Connor, F. M., Roberts, M. J., Rodriguez, J. M., Woodward, S., Best, M. J., Brooks, M. E., Brown, A. R., Butchart, N., Dearden, C., Derbyshire, S. H., Dharssi, I., Doutriaux-Boucher, M., Edwards, J. M., Falloon, P. D., Gedney, N., Gray, L. J., Hewitt, H. T., Hobson, M., Huddleston, M. R., Hughes, J., Ineson, S., Ingram, W. J., James, P. M., Johns, T. C., Johnson, C. E., Jones, A., Jones, C. P., Joshi, M. M., Keen, A. B., Liddicoat, S., Lock, A. P., Maidens, A. V., Manners, J. C., Milton, S. F., Rae, J. G. L., Ridley, J. K., Sellar, A., Senior, C. A., Totterdell, I. J., Verhoef, A., Vidale, P. L., and Wiltshire, A.: The HadGEM2 family of Met Office Unified Model climate configurations, Geosci. Model Dev., 4, 723-757, https://doi.org/10.5194/gmd-4-723-2011, 2011.

van den Hurk, B., Kim, H., Krinner, G., Seneviratne, S. I., Derksen, C., Oki, T., Douville, H., Colin, J., Ducharne, A., Cheruy, F., Viovy, N., Puma, M. J., Wada, Y., Li, W., Jia, B., Alessandri, A., Lawrence, D. M., Weedon, G. P., Ellis, R., Hagemann, S., Mao, J., Flanner, M. G., Zampieri, M., Materia, S., Law, R. M., and Sheffield, J.: LS3MIP (v1.0) contribution to CMIP6: the Land Surface, Snow and Soil moisture Model Intercomparison Project - aims, setup and expected outcome, Geosci. Model Dev., 9, 2809-2832, https://doi.org/10.5194/gmd-9-2809-2016, 2016.

Van Genuchten, M.: A closed-form equation for predicting the hydraulic conductivity of unsaturated soils 1 , Soil Sci. Am. J., 44, 892-898, available at: https://dl.sciencesocieties.org/ publications/sssaj/abstracts/44/5/SS0440050892 (last access: 4 December 2018), 1980.

Vionnet, V., Brun, E., Morin, S., Boone, A., Faroux, S., Le Moigne, P., Martin, E., and Willemet, J.-M.: The detailed snowpack scheme Crocus and its implementation in SURFEX v7.2, Geosci. Model Dev., 5, 773-791, https://doi.org/10.5194/gmd-5773-2012, 2012.

Walters, D., Baran, A. J., Boutle, I., Brooks, M., Earnshaw, P., Edwards, J., Furtado, K., Hill, P., Lock, A., Manners, J., Morcrette, C., Mulcahy, J., Sanchez, C., Smith, C., Stratton, R., Tennant, W., Tomassini, L., Van Weverberg, K., Vosper, S., Willett, M., Browse, J., Bushell, A., Carslaw, K., Dalvi, M., Essery, R., Gedney, N., Hardiman, S., Johnson, B., Johnson, C., Jones, A., Jones, C., Mann, G., Milton, S., Rumbold, H., Sellar, A., Ujiie, M., Whitall, M., Williams, K., and Zerroukat, M.: The Met Office Unified Model Global Atmosphere 7.0/7.1 and JULES Global Land 7.0 configurations, Geosci. Model Dev., 12, 1909-1963, https://doi.org/10.5194/gmd-12-1909-2019, 2019.

Walters, D. N., Best, M. J., Bushell, A. C., Copsey, D., Edwards, J. M., Falloon, P. D., Harris, C. M., Lock, A. P., Manners, J. C., Morcrette, C. J., Roberts, M. J., Stratton, R. A., Webster, S., 
Wilkinson, J. M., Willett, M. R., Boutle, I. A., Earnshaw, P. D., Hill, P. G., MacLachlan, C., Martin, G. M., Moufouma-Okia, W., Palmer, M. D., Petch, J. C., Rooney, G. G., Scaife, A. A., and Williams, K. D.: The Met Office Unified Model Global Atmosphere 3.0/3.1 and JULES Global Land 3.0/3.1 configurations, Geosci. Model Dev., 4, 919-941, https://doi.org/10.5194/gmd-4919-2011, 2011.

Walters, D. N., Williams, K. D., Boutle, I. A., Bushell, A. C., Edwards, J. M., Field, P. R., Lock, A. P., Morcrette, C. J., Stratton, R. A., Wilkinson, J. M., Willett, M. R., Bellouin, N., BodasSalcedo, A., Brooks, M. E., Copsey, D., Earnshaw, P. D., Hardiman, S. C., Harris, C. M., Levine, R. C., MacLachlan, C., Manners, J. C., Martin, G. M., Milton, S. F., Palmer, M. D., Roberts, M. J., Rodríguez, J. M., Tennant, W. J., and Vidale, P. L.: The Met Office Unified Model Global Atmosphere 4.0 and JULES Global Land 4.0 configurations, Geosci. Model Dev., 7, 361-386, https://doi.org/10.5194/gmd-7-361-2014, 2014.

Williams, K. D., Copsey, D., Blockley, E. W., Bodas-Salcedo, A., Calvert, D., Comer, R., Davis, P., Graham, T., Hewitt, H. T., Hill, R., Hyder, P., Ineson, S., Johns, T. C., Keen, A. B., Lee, R. W., Megann, A., Milton, S. F., Rae, J. G. L., Roberts, M. J., Scaife, A. A., Schiemann, R., Storkey, D., Thorpe, L., Watterson, I. G., Walters, D. N., West, A., Wood, R. A., Woollings, T., and Xavier, P. K.: The Met Office Global Coupled Model 3.0 and 3.1 (GC3.0 and GC3.1) Configurations, J. Adv. Model. Earth Sy., 10, 357380, https://doi.org/10.1002/2017MS001115, 2018.
Yang, W., Tan, B., Huang, D., Rautiainen, M., Shabanov, N. V., Wang, Y., Privette, J. L., Huemmrich, K. F., Fensholt, R., Sandholt, I., Weiss, M., Ahl, D. E., Gower, S. T., Nemani, R. R., Knyazikhin, Y., and Myneni, R. B.: MODIS leaf area index products: From validation to algorithm improvement, IEEE T. Geosci. Remote, 44, 1885-1896, https://doi.org/10.1109/TGRS.2006.871215, 2006.

Yen, Y.-C.: Review of the thermal properties of snow, ice and sea ice, 81-10, Technical Report, Cold Regions Research and Engineering Laboratory, Hanover, NH, 1981. 